\title{
Modulation of Apoptosis Pathways by Oxidative Stress and Autophagy in $\beta$ Cells
}

\author{
Maorong Wang, ${ }^{1}$ Mia Crager, ${ }^{1}$ and Subbiah Pugazhenthi ${ }^{1,2}$ \\ ${ }^{1}$ Section of Endocrinology, Veterans Affairs Medical Center, Denver, CO 80220, USA \\ ${ }^{2}$ Department of Medicine, University of Colorado Denver School of Medicine, Aurora, CO 80045, USA
}

Correspondence should be addressed to Subbiah Pugazhenthi, subbiah.pugazhenthi@ucdenver.edu

Received 30 June 2011; Accepted 27 November 2011

Academic Editor: Muthuswamy Balasubramanyam

Copyright (C) 2012 Maorong Wang et al. This is an open access article distributed under the Creative Commons Attribution License, which permits unrestricted use, distribution, and reproduction in any medium, provided the original work is properly cited.

\begin{abstract}
Human islets isolated for transplantation are exposed to multiple stresses including oxidative stress and hypoxia resulting in significant loss of functional $\beta$ cell mass. In this study we examined the modulation of apoptosis pathway genes in islets exposed to hydrogen peroxide, peroxynitrite, hypoxia, and cytokines. We observed parallel induction of pro- and antiapoptotic pathways and identified several novel genes including BFAR, CARD8, BNIP3, and CIDE-A. As BNIP3 is an inducer of autophagy, we examined this pathway in MIN6 cells, a mouse beta cell line and in human islets. Culture of MIN6 cells under low serum conditions increased the levels of several proteins in autophagy pathway, including ATG4, Beclin 1, LAMP-2, and UVRAG. Amino acid deprivation led to induction of autophagy in human islets. Preconditioning of islets with inducers of autophagy protected them from hypoxiainduced apoptosis. However, induction of autophagy during hypoxia exacerbated apoptotic cell death. ER stress led to induction of autophagy and apoptosis in $\beta$ cells. Overexpression of MnSOD, an enzyme that scavenges free radicals, resulted in protection of MIN6 cells from cytokine-induced apoptosis. Ceramide, a mediator of cytokine-induced injury, reduced the active phosphorylated form of Akt and downregulated the promoter activity of the antiapoptotic gene bcl-2. Furthermore, cytokine-stimulated JNK pathway downregulated the bcl-2 promoter activity which was reversed by preincubation with SP600125, a JNK inhibitor. Our findings suggest that $\beta$ cell apoptosis by multiple stresses in islets isolated for transplantation is the result of orchestrated gene expression in apoptosis pathway.
\end{abstract}

\section{Introduction}

The major pathways of apoptosis are the extrinsic pathway, initiated by Fas and other death receptors resulting in the activation of caspase- 8 , and the intrinsic mitochondrial pathway, regulated by Bcl-2 family of proteins leading to the activation of caspase- $9[1,2]$. These two pathways converge with the activation of caspase-3. Both apoptotic pathways are involved in $\beta$ cell death in type 1 and type 2 diabetes [3]. Fas (CD95/APO-1) is a $36-\mathrm{kD}$ death receptor protein that initiates apoptosis in many cell types when cross-linked to Fas ligand (FasL/CD95L) [4]. A histological study of human diabetic pancreas biopsies has demonstrated Fas expression on $\beta$ cells and FasL expression on the infiltrating cells [5]. However, the intrinsic mitochondrial pathway, regulated by the $\mathrm{Bcl}-2$ family of proteins, consisting of proapoptotic (Bax and Bak1) and antiapoptotic (Bcl-2, Bcl$\mathrm{xL}, \mathrm{Mcl}-1$, etc.) proteins [6], has been shown to play a predominant role in the loss of isolated islets [7]. Imbalance between these two groups of proteins results in the release of cytochrome c, which activates caspase-9 [2]. BH3-only proteins, a subset of proapoptotic proteins, act as sensors of cellular stress $[8,9]$. Members of this family include Bad, Bid, Bmf, Hrk, Bim, Bik, Noxa, and Puma. They induce apoptosis by activating proapoptotic proteins or by neutralizing antiapoptotic proteins. Bid cleaved by caspase8 translocates to mitochondria and causes cytochrome $\mathrm{c}$ release, thus linking the two pathways of apoptosis [10].

Autophagy is a lysosomal degradative pathway that provides energy through self-digestion under conditions of starvation. During oxidative stress, autophagy serves as a defense mechanism to clear oxidatively damaged proteins 
and organelles [11]. There are three major pathways of autophagy: (1) chaperone-mediated autophagy (CMA), which is found in mammalian cells alone and degrades cytosolic proteins selectively; (2) microautophagy, whereby lysosomes directly engulf cytosolic constituents through invaginations of the lysosomal membrane; and (3) macroautophagy (referred to as autophagy), in which cytosolic contents including organelles and proteins are sequestered within double-membrane structures called autophagosomes that fuse with lysosomes and lead to degradation. A series of maturation steps involving the ATG family of proteins are involved in the formation of autophagosomes. Among the 30 ATG genes identified in yeast, 11 (ATG1, 3-10, 12, and 16) have orthologs in mammalian cells. Autophagic vesicles contain multiple proteins, including Type (or Class) III PI3 kinase (vps34), Beclin 1 (ATG6), UVRAG, and Ambra. An important step in the formation of autophagosomes is the conjugation of LC3 (ATG8) with phosphatidylethoanlamine to form LC3-PE (LC3-II) which is a standard marker for autophagy. Extensive autophagy could lead to type 2 cell death, a second mode of programmed cell death [12]. Aged insulin-secreting granules in $\beta$ cells are degraded by crinophagy [13]. An imbalance between insulin production and secretion, which is likely to occur in type 2 diabetes, induces autophagy to degrade accumulated insulin granules [14]. Ubiquitinated protein aggregates that accumulate in $\beta$ cells of islets in obese Zucker rats have been shown to stimulate autophagy [15]. Increased autophagic activity has been observed in the islets of Rab3 $\mathrm{A}^{-/-}$mice which display a defect in insulin secretion [13].

Islets are clusters of different cell types including $\alpha$, $\beta, \delta$, and PP cells, with insulin-producing $\beta$ cells being the major component (70-80\%). The blood vessels inside islets are essential for the supply of oxygen, nutrients, and secretion of hormones. These vessels are disrupted during the islet isolation process. Thus, islets are vulnerable to injury in the early stages after transplantation due to the delay in revascularization [16]. Even after revascularization, the vascular density is considerably less compared to endogenous islets [17]. The expression of genes associated with angiogenesis is decreased in diabetic transplant recipients, further delaying the revascularization process [18]. The molecular mechanism of apoptosis in $\beta$ cells of islets in the transplantation setting is not clearly understood. The objective of the present study was to profile the expression of apoptosis pathway genes in human islets exposed to stresses associated with islet isolation and transplantation and to determine the role of stress-signaling pathways.

\section{Experimental Procedures}

2.1. Culture of Human Islets and MIN6 Cells. Human islets isolated from cadaveric donors were provided by Integrated Islet Distribution Program (IIDP). Islets with purity of $70 \%$ to $95 \%$ and the viability of $70 \%-95 \%$ were used. Islets were cultured in CMRL 1066 medium (Mediatech Inc., Hendon, VA) supplemented with human serum albumin $(0.5 \%$; Octapharma, Vienna, Austria) and nicotinamide (10 mM) and referred to as Miami medium. To induce hypoxia in islets, culture dishes were placed inside a modular incubation chamber (Billups Rothenberg, Del Mar, CA) and flushed with a gas supply of $1 \%$ oxygen, $5 \% \mathrm{CO}_{2}$, and $94 \% \mathrm{~N}_{2}$ for $20 \mathrm{~min}$. The chamber was then placed inside the cell culture incubator. MIN6 cells, a mouse pancreatic $\beta$ cell line [19], obtained from Dr. Miyazaki (Kyoto University, Japan) were cultured in RPMI medium containing 10\% FBS (Gemini Bioproducts, Sacramento, CA), $100 \mu \mathrm{g} / \mathrm{mL}$ streptomycin (Gemini Bioproducts), $100 \mathrm{U} / \mathrm{mL}$ penicillin (Gemini Bioproducts), and $50 \mu \mathrm{M} \beta$-mercaptoethanol (BME; Sigma Aldrich, St. Louis, $\mathrm{MO}$ ) at $37^{\circ} \mathrm{C}$ in a humidified atmosphere of $5 \% \mathrm{CO}_{2}$. Autophagy was induced in MIN6 cells by culturing them in low serum $(0.1 \%)$ serum-containing medium and in human islets by amino acid deprivation.

2.2. Gene Expression Profiling of Apoptosis Pathways. Human islets isolated from donor pancreas were exposed to Hydrogen peroxide, peroxynitrite, hypoxia, or a combination of cytokines (IL- $1 \beta$, TNF- $\alpha$, and IFN- $\gamma$ ). A pathway-specific, PCR-based array (SABioscience, Frederick, MD) was performed to determine the expression of a panel of genes in apoptosis pathway (listed in Table 1). RNA samples following DNase treatment were converted to CDNA by the following procedure: $1 \mu \mathrm{g}$ of RNA was reverse transcribed in a $50 \mu \mathrm{L}$ reaction mixture with $125 \mathrm{U}$ of Moloney Murine leukemia virus reverse transcriptase, $20 \mathrm{U}$ RNasin ribonuclease inhibitor, $4 \mathrm{mM}$ deoxyribonucleoside triphosphates, $5 \mathrm{mM} \mathrm{MgCl}_{2}$, 1X PCR Buffer II, and $0.5 \mu \mathrm{g}$ of random hexanucleotide primers (Applied Biosystems, Carlsbad, CA). The reaction mixture was sequentially incubated at $65^{\circ} \mathrm{C}$ for $5 \mathrm{~min}, 42^{\circ} \mathrm{C}$ for $60 \mathrm{~min}$, and the reverse transcription reaction was stopped by heating to $95^{\circ} \mathrm{C}$ for $5 \mathrm{~min}$ and cooled to $4^{\circ} \mathrm{C}$. The experimental cocktail was prepared by adding $102 \mu \mathrm{L}$ of the diluted cDNA to $1278 \mu \mathrm{L}$ of the $\mathrm{RT}^{2}$ qPCR master mix containing SYBR Green (SA Biosciences, Frederick, MD) and $1173 \mu \mathrm{L} \mathrm{H}_{2} \mathrm{O} .25 \mu \mathrm{L}$ of this cocktail was added to each well of the 96-well PCR array plate containing primers for the 84 genes in apoptotic pathway, five housekeeping control genes, and three RNA and PCR quality controls. Real-time PCR was performed in an ABI Prism 7700 sequence detector (Applied Biosystems, Foster City, CA). The thermal cycling conditions were 1 cycle of 10 minutes at $95^{\circ} \mathrm{C}$ followed by 40 cycles of 15 seconds at $95^{\circ} \mathrm{C}$ and of 1 minute at $60^{\circ} \mathrm{C}$. After amplification, real-time data acquisition and analysis were performed through the Data Analysis Web Portal (SA Biosciences). Data analysis is based on the delta-delta $\mathrm{Ct}$ method with normalization of the raw data to GAPDH as described in the manufacturer's manual.

2.3. RNA Isolation and Real-Time Quantitative RT-PCR. Total RNA was isolated from treated islets. After DNAse treatment, RNA integrity was determined by capillary electrophoresis using RNA 6000 Nano LabChip. The mRNA levels of selected genes (BFAR, CARD8, CIDE-A, and BNIP3) identified in the expression profiling described previously were examined by real-time quantitative RT-PCR using Taqman probes. Assay on Demand (Applied Biosystems) was 
used for BNIP3. The sequence for primers and probes for other targets is as follows:

\section{BFAR \\ Forward Primer: GGAGGACATCGTCACCAAGC \\ Reverse Primer: AGTATTTGACCAGGAACTCTCT CCA}

TaqMan Probe: $5^{\prime}$-6FAM-TCTGGATCTTAAGGAG CCTACGTGGAAGCA-TAMRA-3'

CARD8

Forward Primer: GACTTCCGGTCGCCATGAT

Reverse Primer: ACCATTGAAGATGGCCCAGA

TaqMan Probe: 5'-6FAM-TGGGCGGTAAACGCG GTTAGTGC-TAMRA-3'

\section{CIDE- $A$}

Forward Primer: TCTTTCAGACCTTGGGAGACA AC

Reverse Primer: TGGCTGCCCGGCATC

TaqMan Probe: 5'-6FAM-CGCATTTCATGATCTT GGAAAAAGGACAGA-TAMRA-3'.

The PCR reactions were monitored in real time in an ABI Prism 7700 sequence detector (Perkin Elmer Corp./Applied Biosystems). After amplification, real-time data acquisition and analysis were performed.

2.4. Western Blot Analysis. MIN6 cells and human islets exposed to stress conditions were washed with ice-cold PBS and lysed with mammalian protein extraction reagent (MPER, Pierce, Rockford, Illinois, USA) supplemented with phosphatase inhibitors $(20 \mathrm{mM}$ of sodium fluoride, $1 \mathrm{mM}$ of sodium orthovanadate and $500 \mathrm{nM}$ of okadaic acid) and protease inhibitors (Sigma P8340). Lysates were centrifuged at $20,800 \times \mathrm{g}$, and the protein concentration was determined in the supernatant samples by a dye-binding method [20]. Diluted samples containing equal amounts of protein were mixed with $2 \mathrm{X}$ Laemmli sample buffer. The proteins were resolved on a $12 \%$ SDS-polyacrylamide gels. Following transfer to PVDF membranes (Millipore, Bedford, MA), the blots were blocked with TBST (20 mM Tris- $\mathrm{HCl}$ ( $\mathrm{pH}$ 7.9), $8.5 \% \mathrm{NaCl}$, and $0.1 \%$ Tween 20 ) containing $5 \%$ non-fat dry milk at room temperature (RT) for $1 \mathrm{~h}$ and exposed to primary antibodies (1:1000; Cell Signaling, Danvers, MA) in TBST containing $5.0 \% \mathrm{BSA}$ at $4^{\circ} \mathrm{C}$ overnight. The blots were washed with TBST and anti-rabbit IgG conjugated to alkaline phosphatase (Cell Signaling) was added for one hour at RT. After incubation in the presence of alkaline buffer (10 mM Tris- $\mathrm{HCl}$ (pH 9.5), $10 \mathrm{mM}, \mathrm{NaCl}$ and $1 \mathrm{mM} \mathrm{MgCl}_{2}$ ), signals were developed with CDP-Star reagent (New England Biolabs, Beverly, MA) and exposed to X-ray film. The intensity of bands was measured using Fluor-S MultiImager and Quantity One software from Bio-Rad.
2.5. Transfection Procedure. The activity of bcl-2 promoter (truncated with CRE site, -1640-1287) linked to firefly luciferase reporter gene (provided by Linda Boxer, Stanford University School of Medicine) was measured in cultured MIN6 cells by a transient transfection assay using the procedure described earlier [21]. Plasmids $(2 \mu \mathrm{g})$ and LipofectAMINE reagent 2000 (Invitrogen-Life Technologies, Carlsbad, CA) $(4 \mu \mathrm{L})$ were diluted separately in $100 \mu \mathrm{L}$ of Opti-MEM I, mixed, and incubated at room temperature for 20 min. A constitutively active renilla luciferase (pRL-TKluc) was included to correct for transfection efficiency and for nonspecific actions of treatments on luciferase activity. The plasmid mixture were added to MIN6 cells cultured in 12 well dishes to about $70 \%$ confluence. The transfected MIN6 cells were cultured in low serum $(0.1 \%)$ medium with appropriate treatment. The treated cells were washed with cold PBS and lysed with $100 \mu \mathrm{L}$ of reporter lysis buffer. The lysate was centrifuged $(10,600 \times \mathrm{g} ; 20 \mathrm{~min})$ to collect the supernatant. The activities of firefly luciferase and renilla luciferase were measured using a dual luciferase assay kit (Promega, Madison, WI). The ratios of these two luciferase activities were taken as the measure of bcl-2 promoter induction.

2.6. Immunocytochemistry. MIN6 cells were cultured in a Lab-Tek II Chamber Slide system; following transfection and treatment, they were fixed in $4 \%$ paraformaldehyde for 30 minutes at RT. After washing with PBS, fixed cells were permeabilized in PBS containing $0.2 \%$ Triton X-100 and $5 \%$ BSA for 90 minutes. The cells were incubated in the presence of antibodies for active caspase- 9 or active caspase- $3(1: 250)$ in $3 \% \mathrm{BSA}$ at $4^{\circ} \mathrm{C}$ overnight, washed in PBS, and exposed to secondary antibodies linked to Cy3 (Jackson ImmunoResearch Laboratories, West Grove, Pennsylvania, USA) in 3\% BSA for 90 minutes at RT. Cells were then washed in PBS, sealed with mounting medium and examined by digital deconvolution microscopy using a Zeiss Axioplan 2 microscope fitted with Cooke SensiCam ${ }^{\mathrm{QE}}$ high performance CCD camera. Immunocytochemistry with islets was carried out by a similar procedure but with islets in suspension. Primary antibodies were at the dilution of $1: 2000$ for insulin and 1:500 for LC3-II and phosphorylated Akt. Appropriate secondary antibodies linked to Cy3 or FITC in $3 \%$ BSA were used. Washing steps were performed by centrifugation at $500 \mathrm{RPM}$ for $5 \mathrm{~min}$. After the final step of washing the fluorescent labeled islets in PBS, they were suspended in mounting medium and placed inside secure seal hybridization chambers for fluorescent microscopy. Images were taken in multiple $z$-planes and assembled together by digital deconvolution microscopy.

Statistical analysis was performed by one-way analysis of variance (ANOVA) with Dunnett's multiple comparison test.

\section{Results}

3.1. Gene Expression Profiling of Apoptosis Pathways in Human Islets under Stress. We performed an apoptosis pathwayspecific gene expression array with RNA isolated from 
TABLE 1: Functional grouping of apoptosis pathway genes.

\begin{tabular}{ll}
\hline Bcl-2 family & BAD, BAG1, BAG3, BAG4, BAK1, BAX, BCL2, BCL2A1, BCL2L1, BCL2L10, BCL2L11, BCL2L2, \\
Caspase family & BCLAF1, BID, BIK, BNIP1, BNIP2, BNIP3, BNIP3L, HRK, MCL1 \\
IAP family & CASP1, CASP10, CASP14, CASP2, CASP3, CASP4, CASP5, CASP6, CASP7, CASP8, CASP9 \\
TRAF family & BIRC1, BIRC2, BIRC3, BIRC4, BIRC6, BIRC8 \\
CARD family & APAF2, TRAF3, TRAF4 \\
& CRADD, NOL3, PYCARD, RIPK2 \\
Death domain family & CRADD, DAPK1, FADD, FAS (TNFRSF6), TNFRSF10A, TNFRSF10B, TNFRSF11B, TNFRSF1A, \\
Death effector domain family & CASP8, CASP10, CFLAR, FADD \\
CIDE domain family & CIDE-A, CIDE-B, DFFA \\
p53 and DNA damage response & ABL1, AKT1, APAF1, BAD, BAX, BCL2, BCL2L1, BID, CASP3, CASP6, CASP7, CASP9, GADD45A, \\
& TP53, TP53BP2, TP73 \\
Anti-apoptosis & AKT1, BAG1, BAG3, BCL2, BCL2A1, BCL2L1, BCL2L10, BCL2L2, BFAR, BIRC1, BIRC2, BIRC3, \\
TNF ligand family & CDC4, BIRC6, BIRC8, BNIP1, BNIP2, BNIP3, BRAF, CFLAR, IGF1R, MCL1, TNFRSF7 \\
TNF receptor family & CD40 (TNFRSF), FAS (TNFRSF6), LTBR, TNFRSF10A, TNFRSF10B, TNFRSF11B, TNFRSF1A, \\
\hline
\end{tabular}

TABLE 2: Mean fold (>2.0) changes in apoptosis pathway gene expression in islets after exposure to oxidative stress $\left(\mathrm{H}_{2} \mathrm{O}_{2}\right.$ and peroxynitrite), hypoxia, and cytokines.

\begin{tabular}{|c|c|c|c|c|c|}
\hline Genes & Role in apoptosis & Peroxynitrite & $\mathrm{H}_{2} \mathrm{O}_{2}$ & Hypoxia & Cytokines \\
\hline $\mathrm{Bcl} 2 \mathrm{~A} 1$ & Anti-apoptotic; Bcl2 family & 3.2 & 2.1 & 2.4 & 11.4 \\
\hline Bid & Proapoptotic; BH3 only & 3.7 & 3.5 & 2.5 & 3.4 \\
\hline Fas & Extrinsic; receptor & 4.3 & 3.1 & 3.4 & 7.4 \\
\hline Fas ligand & Extrinsic; receptor ligand & 2.4 & 2.1 & NS & 3.4 \\
\hline TRAIL & Extrinsic; receptor ligand & 4.6 & 3.6 & NS & 4.2 \\
\hline A20 & Extrinsic; anti-apoptotic & 2.3 & NS & 2.5 & 7.4 \\
\hline c-Flip & Extrinsic; anti-apoptotic & 2.6 & NS & NS & 4.2 \\
\hline Caspase-3 & Marker for apoptosis & 4.5 & 3.2 & 3.2 & 2.3 \\
\hline BIRC3 & Caspase inhibitor & 3.2 & 2.4 & NS & 8.7 \\
\hline CARD8 & Caspase-9 inhibitor & -2.3 & -2.4 & -2.1 & -2.3 \\
\hline BRAF & Signaling kinase & -3.7 & -3.5 & -2.5 & NS \\
\hline BFAR & Anti-apoptotic; links both pathways & -4.8 & -3.5 & -4.2 & NS \\
\hline CIDE-A & Causes DNA fragmentation & 3.2 & 2.4 & 3.8 & NS \\
\hline BNIP3 & Autophagy Inducer & 2.6 & NS & 5.6 & NS \\
\hline
\end{tabular}

Human islets (2000 IEQ) were exposed to $200 \mu \mathrm{M}$ of peroxynitrite, $200 \mu \mathrm{M}$ of $\mathrm{H}_{2} \mathrm{O}_{2}$ or a mixture of cytokines $(2 \mathrm{ng} / \mathrm{mL}$ of IL- $1 \beta, 10 \mathrm{ng} / \mathrm{mL}$ of TNF- $\alpha$ and $10 \mathrm{ng} / \mathrm{mL}$ of IFN- $\gamma$ ) for $24 \mathrm{~h}$ or cultured under hypoxic conditions (1\% oxygen) for $8 \mathrm{~h}$. The cDNA synthesized from isolated RNA was mixed with Master Mix containing SYBR Green and distributed into 96 wells containing primers for the 84 genes associated with the apoptotic pathway. Five housekeeping control genes and three RNA and PCR quality controls were also included. PCR analysis was carried out and the fold changes between control and treated were calculated based on $\Delta C_{t}$ and corrected for GAPDH expression. Results are the mean obtained from four different batches of human islets. NS: not significant.

human islets exposed to oxidative stress, hypoxia and proinflammatory cytokines. Genes in intrinsic and extrinsic pathways were induced in stressed islets (Table 2). For example, Fas, fas ligand, and TRAIL, important regulators of the extrinsic pathway, were induced $(150-360 \%)$ by oxidative stress and cytokines. Bid that links both pathways was induced by $150-270 \%$. The expression of CARD8, an inhibitor of caspase-9, a marker for the intrinsic pathway of apoptosis, was downregulated $\sim 50 \%$ by oxidants, hypoxia, and cytokines. Downregulation of BRAF (60-73\%), a critical signaling kinase, suggests that these islets are likely to be less responsive to growth factor-mediated cell survival pathways. Caspase-3, a marker for apoptosis, is activated by proteolytic cleavage. In this study, we also observed increased expression of caspase-3 by all the stresses tested. CIDE-A which causes DNA fragmentation was induced (140-280\%) 


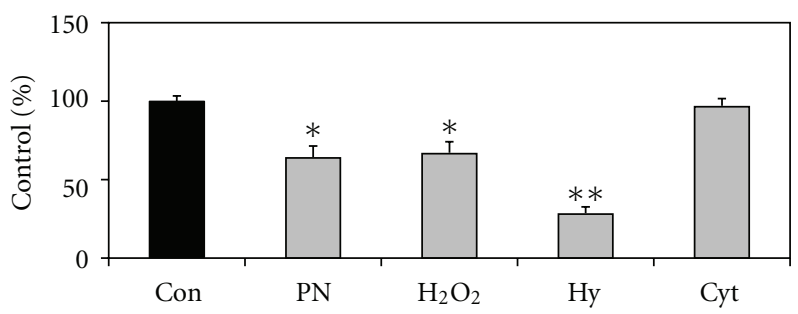

(a) BFAR

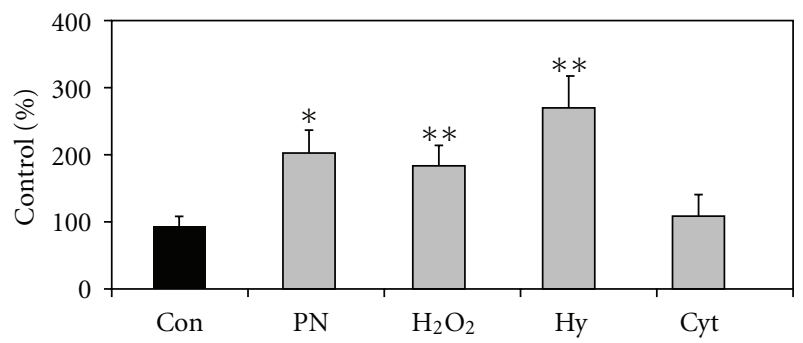

(c) CIDE-A

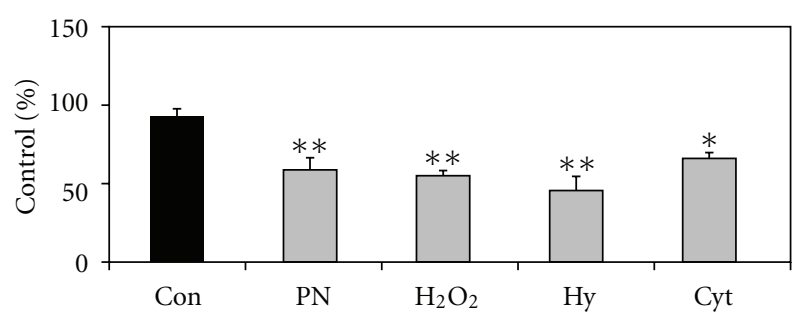

(b) CARD8

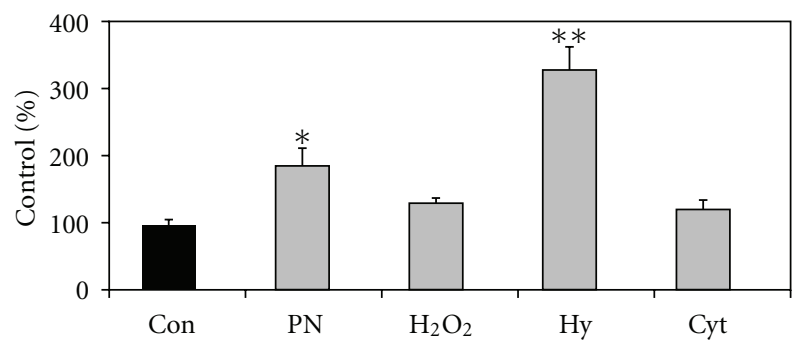

(d) BNIP3

FIGURE 1: Stress-induced modulation of genes in apoptosis pathway. Human islets (2000 IEQ) cultured in Miami medium were exposed to multiple stresses including peroxynitrite $(\mathrm{PN} ; 200 \mu \mathrm{M}), \mathrm{H}_{2} \mathrm{O}_{2}(200 \mu \mathrm{M})$, or a mixture of cytokines $(\mathrm{Cyt} ; 2 \mathrm{ng} / \mathrm{mL}$ of IL-1 $\beta, 10 \mathrm{ng} / \mathrm{mL}$ of TNF- $\alpha$, and $10 \mathrm{ng} / \mathrm{mL}$ of IFN- $\gamma$ ) for $24 \mathrm{~h}$ or cultured under hypoxic conditions ( $1 \%$ oxygen) for $8 \mathrm{~h}$. RNA was isolated from treated islets for the RT-PCR analysis of BFAR, CARD8, CIDE-A, and BNIP3 using Taqman probes. Results are M \pm SE of experiments with four independent batches of human islets. ${ }^{*} P<0.01$; ${ }^{* *} P<0.001$ when compared to untreated control (Con).

by oxidative stress and hypoxia. Interestingly, activation of a parallel cytoprotective pathway in response to stress was evident by the induction of several genes in the antiapoptotic pathway including, Bcl2A1, c-IAP2 (BIRC3), A20, and c-flip (CFLAR). BNIP3, an inducer of autophagy was induced by $160 \%$ and $460 \%$ by peroxynitrite and hypoxia, respectively. Our findings from gene expression profiling points to the complex nature of cell death pathway in islets exposed to stresses associated with islet isolation and transplantation.

3.2. Modulation of Apoptosis Pathway Genes in Islets. Some of the genes including BFAR, CARD8, CIDE-A, and BNIP3 listed before have not been reported previously in the context of apoptosis in islets. Therefore, their induction was further confirmed by a more sensitive RT-PCR analysis using Taqman probes. BFAR (bifunctional apoptosis regulator) is a multidomain protein that interacts with members of the extrinsic and intrinsic apoptosis pathways and inhibits apoptosis. CARD8, a member of the caspase-associated recruitment domain (CARD) family, inhibits the activation of caspase-9. Levels of BFAR and CARD8 decreased by $35-40 \%$ when exposed to oxidative stress and by $50-70 \%$ and when incubated under hypoxic conditions (Figure 1). Cytokines decreased (30\%) the expression of CARD8 but not BFAR. The mRNA levels of CIDE-A, a gene that acts downstream of caspases to mediate DNA fragmentation, increased by $95-180 \%$ in islets exposed to oxidative stress while cytokines did not have any effect on the expression of this gene. The expression of BNIP3 which plays an important role in mitochondrial autophagy increased in islets exposed to peroxynitrite $(92 \%)$ and hypoxia $(240 \%)$.
3.3. Induction of Autophagy in MIN6 Cells. Autophagy is a self-digestive process by which cells generate energy during starvation and degrade damaged proteins and organelles. We examined autophagic pathways in MIN6 cells cultured under low serum conditions by Western blot analysis. A key step in the formation of autophagosomes is the conjugation of LC3 (LC3-I-18 kD) with phosphatidylethanolamine to form LC3-PE (LC3-II-16 kD), an important marker of autophagy. As shown in Figure 2(a), the levels of LC3-II increased with increasing concentrations of trehalose, particularly in lowserum medium. The levels of ATG4, LAMP-2, and UVRAG also increased in a similar manner. An increase in Beclin 1 was seen only at $100 \mathrm{mM}$ of trehalose in low-serum medium. Exposure of $\beta$ cells to the autophagy inhibitor 3-methyladenine (3MA) reduced the formation of LC3-II in the presence of trehalose (Figure 2(b)) whereas another inhibitor bafilomycin A1 (Bf) increased the accumulation of LC3-II both under basal conditions as well as following exposure to trehalose (Figure 2(b)) because it interferes at the late lysosomal degradation step leading to accumulation of autophagosomes. Furthermore, induction of ER stress with thapsigargin and tunicamycin (Calbiochem, La Jolla, CA) led to formation LC3-II (Figure 2(c)) suggesting a crosstalk between these two pathways.

3.4. Autophagic Preconditioning Protects Human Islets from Hypoxia-Induced Apoptosis. Amino acid (AA) starvation of human islets by incubation in Hank's balanced salt solution induced autophagy in $\beta$ cells as shown (arrows) by the punctated staining of LC3-II in insulin-positive cells (Figure 3(a)). Autophagy can be protective under conditions 


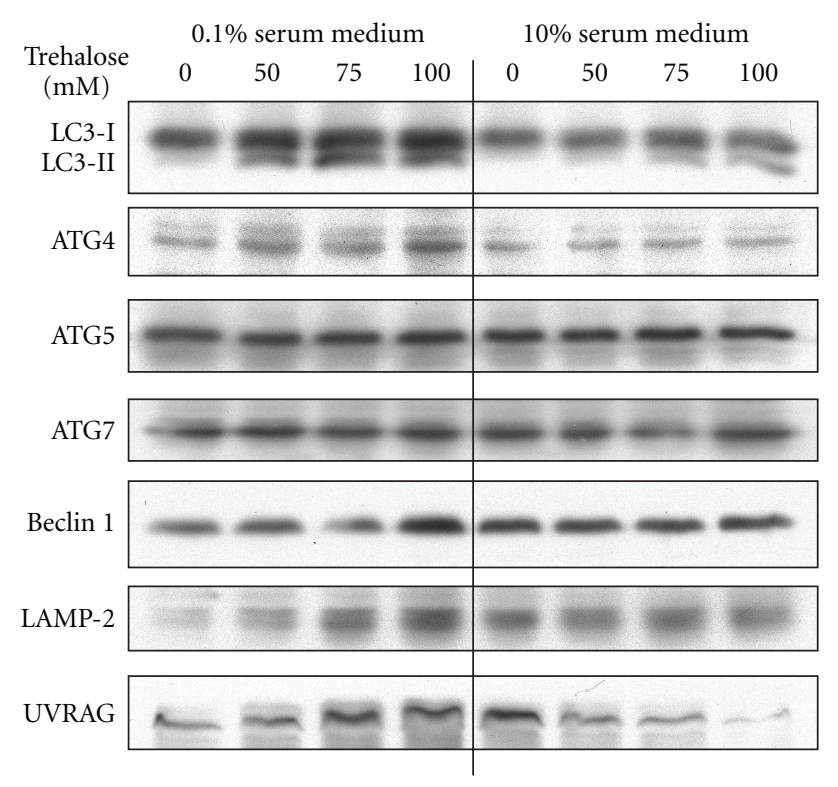

(a)

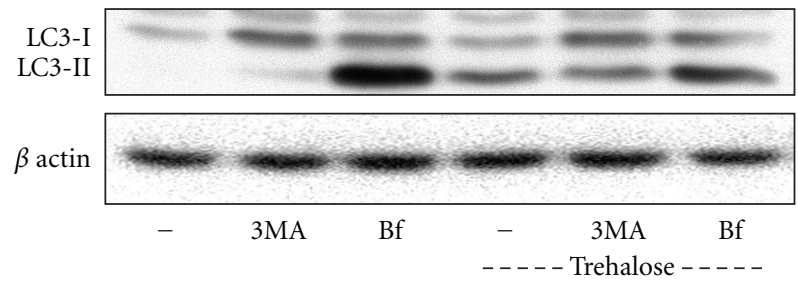

(b)

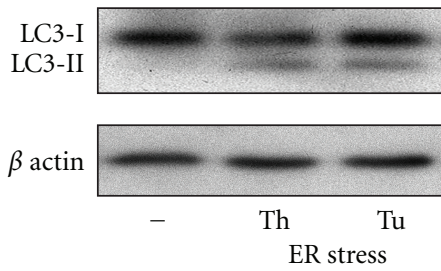

(c)

Figure 2: Induction of autophagy in MIN6 cells. (a) MIN6 cells grown to 60\% confluence were incubated in low (0.1\%) serum or regular $(10 \%)$ serum medium in the presence of increasing concentrations of trehalose, an inducer of autophagy, for $24 \mathrm{~h}$. (b) MIN6 cells were preincubated in the presence of $10 \mathrm{mM}$ of 3-methyladenine (3MA) or $100 \mathrm{nM}$ of bafilomycin A1 (Bf) for 20 min followed by exposure to $100 \mathrm{mM}$ of trehalose for $24 \mathrm{~h}$. (c) ER stress was induced in MIN6 cells by culturing them in the presence of thapsigargin (Th; $100 \mathrm{nM}$ ) or tunicamycin $(\mathrm{Tu} ; 1 \mu \mathrm{g} / \mathrm{mL})$ for $24 \mathrm{~h}$. Lysates of the treated cells $((\mathrm{a})-(\mathrm{c}))$ were analyzed by Western blotting for markers of autophagy. Representative images from three independent experiments are presented.

of starvation in transplanted islets till vascularization takes place. However, excessive autophagy is known to result in cell death through crosstalk with apoptosis. Therefore it becomes a dilemma from a therapeutic angle whether to inhibit or activate autophagy in transplanted islets. To test the strategies for modulation autophagy during hypoxia, we used trehalose, rapamycin, and amino acid starvation as inducers during hypoxia. When islets were exposed to hypoxia in the presence of autophagy inducers, there was exacerbation of apoptosis. Activation of caspase-3 during hypoxia increased further in the presence of trehalose $(40-65 \% ; P<0.01)$, rapamycin $(35 \% ; P<0.05)$, and salt solution $(115 \%$; $P<0.001$ ) (Figure 3(b)) suggesting the need for moderate autophagy during hypoxia. Next we attempted autophagic preconditioning before exposure to hypoxia as an alternate strategy. A high-throughput screen of small molecules [22] has identified among inducers of autophagy, several FDFapproved drugs including Niguldipine, Penitrem A and trifluoperazine. Therefore we screened a number of compounds at different concentrations using MIN6 cells cultured under hypoxia conditions. Based on those results, we tested some of them in human islets by preincubation followed by culture under hypoxic conditions. Significant protection $(P<0.01)$ from hypoxia-induced apoptosis was seen with all the compounds tested (Figure 3(c)). Niguldipine showed that $75 \%$ decreases in active cleaved form of caspase- 3 followed by penitrem (55\%), trifluoperazine $(40 \%)$, and trehalose (35\%).

3.5. Antiapoptotic Actions of MnSOD and Exendin-4 in MIN6 Cells. MnSOD is an antioxidant enzyme that plays an important role in scavenging free radicals generated by oxidative stress. To determine the role of oxidative stress in cytokine-mediated $\beta$ cell apoptosis, a cDNA encoding MnSOD-GFP chimeric protein was overexpressed in MIN6 cells followed by exposure to a mixture of cytokines (IL$1 \beta$, TNF- $\alpha$, and IFN- $\gamma$ ) for $48 \mathrm{~h}$. Activation of caspase9, a marker for the intrinsic pathway of apoptosis, and activation of caspase 3, a general marker for apoptosis, were examined in treated cells by immunofluorescent staining. Cytokines induced apoptosis by the intrinsic pathway in MIN6 cells as shown by the staining for the active forms of 

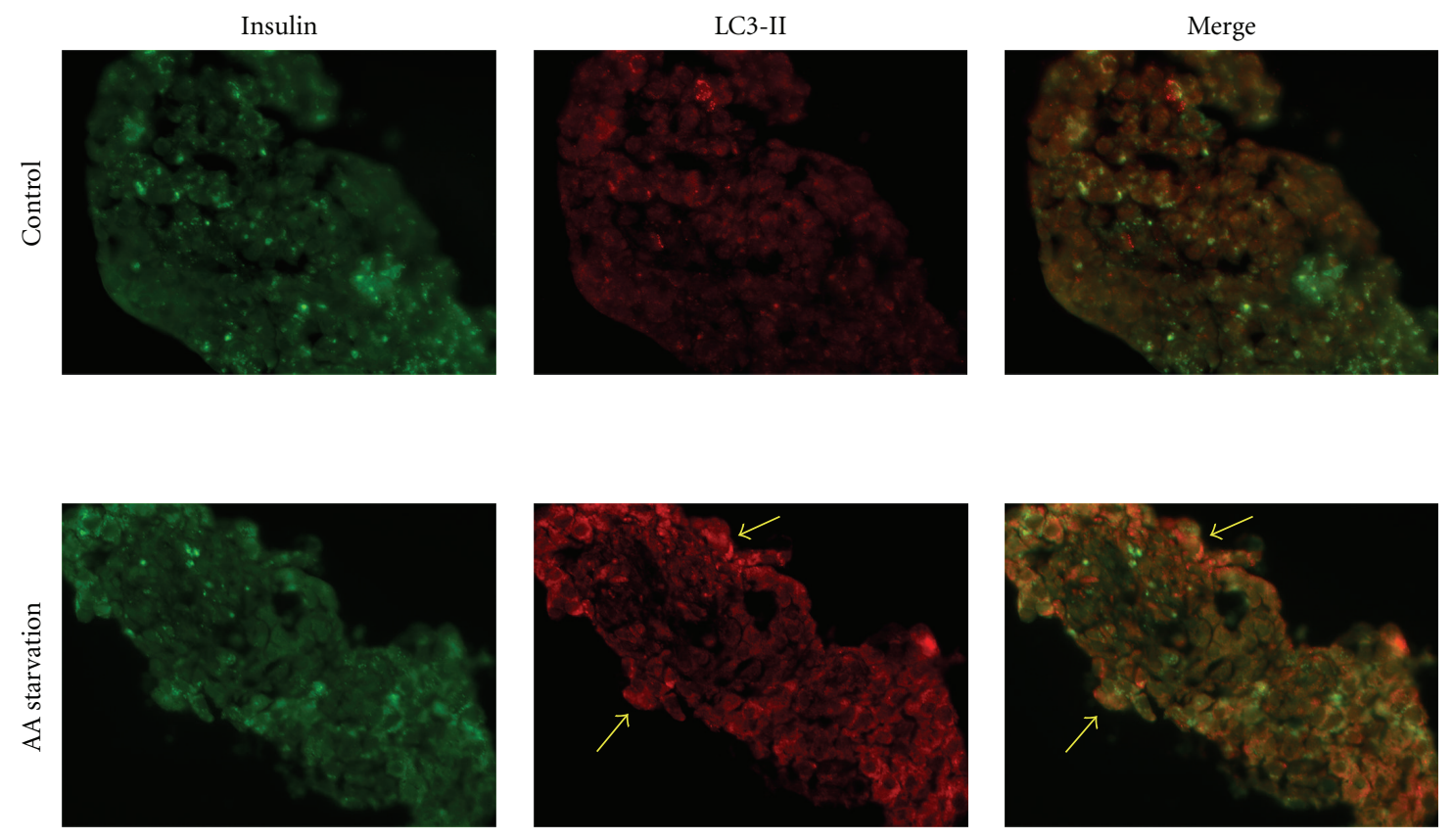

(a)

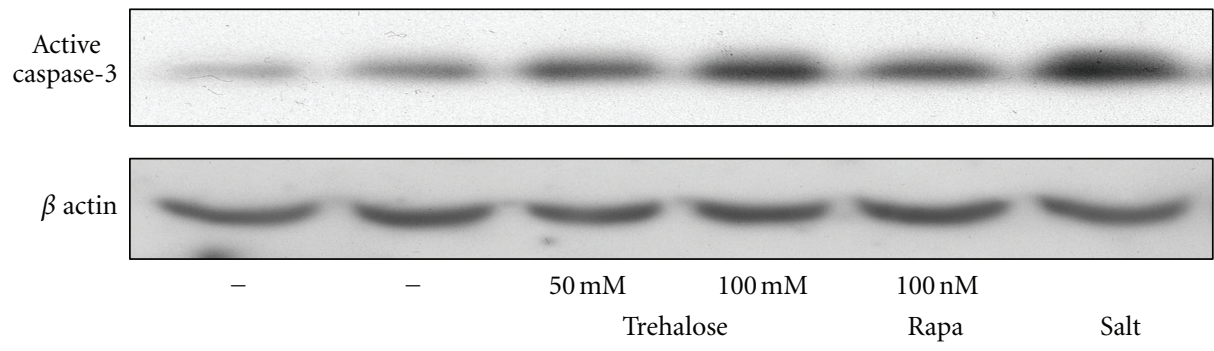

Normoxia - - - - - - - - - - - - Hypoxia - - - - - - - - - - - - - - -

(b)
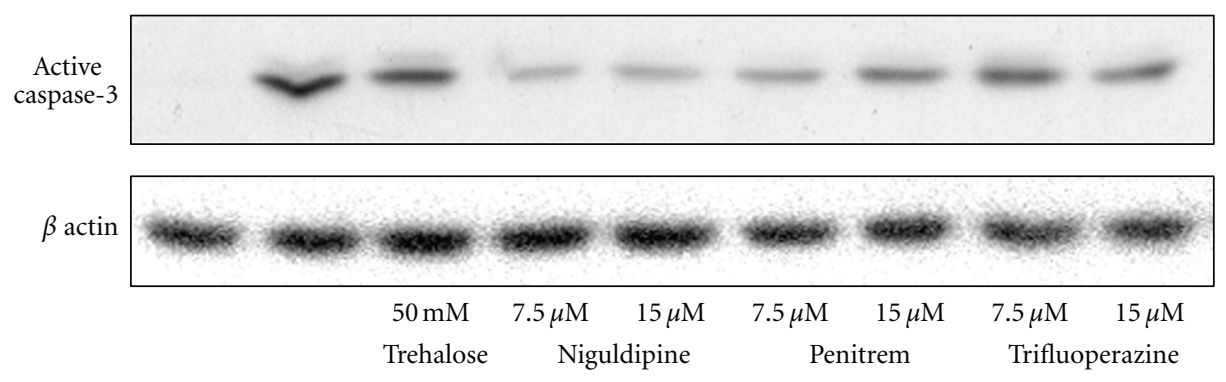

Normoxia -- - - - - - - - - - - - Hypoxia - - - - - - - - - - - - - - -

(c)

FIgURE 3: Induction of autophagy in human islets. (a) Human islets were incubated for $8 \mathrm{~h}$ in Miami medium (control) or in Hank's balanced salt solution for amino acid (AA) starvation. Treated islets were fixed in paraformaldehyde and embedded in OCT. Frozen sections ( $7 \mu \mathrm{m}$ thickness) were immunostained for insulin with FITC (Green) and for LC3-II with cy3 (red). Formation of autophagosomes was visualized by the punctated staining of LC3-II in $\beta$ cells (arrows). (b) Human islets were cultured under normoxic or hypoxic conditions in the absence and presence of inducers of autophagy, trehalose, rapamycin (Rapa) or salt solution (Salt) for $8 \mathrm{~h}$. Cell lysates were processed for Western blot analysis of the active form of caspase-3. Induction of autophagy during hypoxia exacerbated apoptosis in islets. (c) Human islets were preincubated with inducers of autophagy for $4 \mathrm{~h}$. Following change of medium, the cells were cultured under normoxic or hypoxic conditions for $12 \mathrm{~h}$, lysed and processed for the Western blot analysis of active caspase-3. Autophagic preconditioning protected islets from hypoxia-induced apoptosis. Representative images from experiments with three independent batches of human islets are presented. 

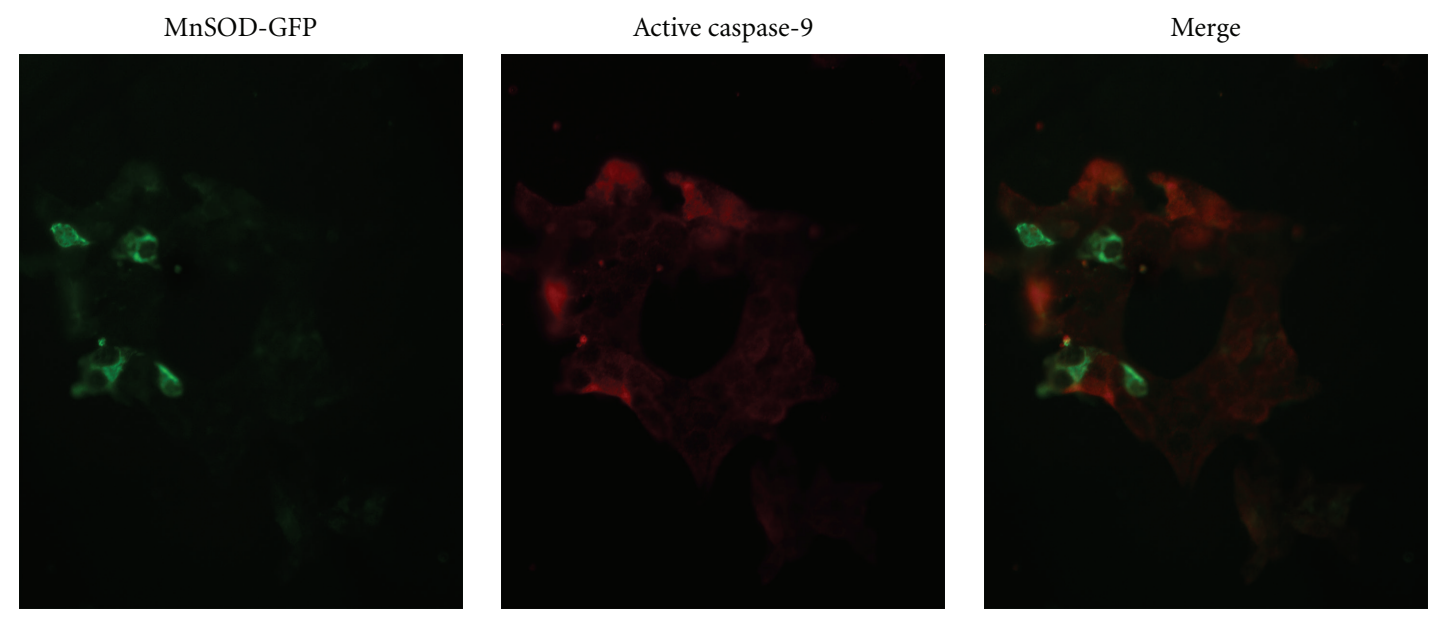

(a)

MnSOD-GFP

Active caspase-3
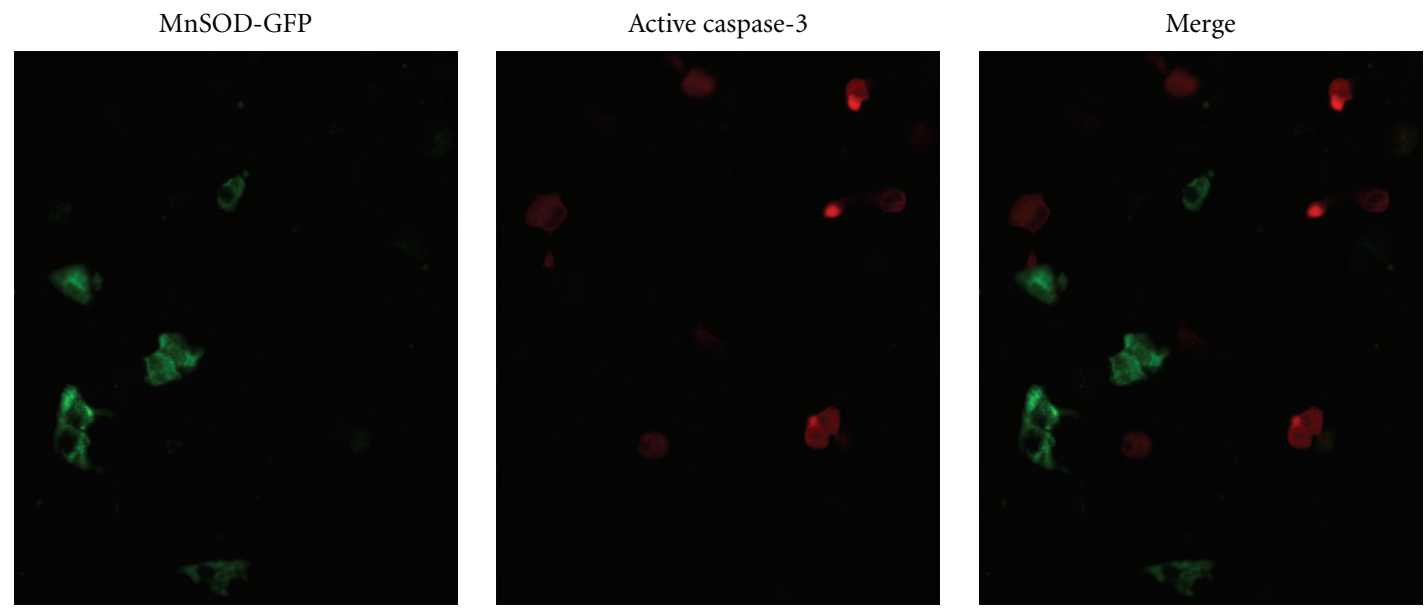

(b)
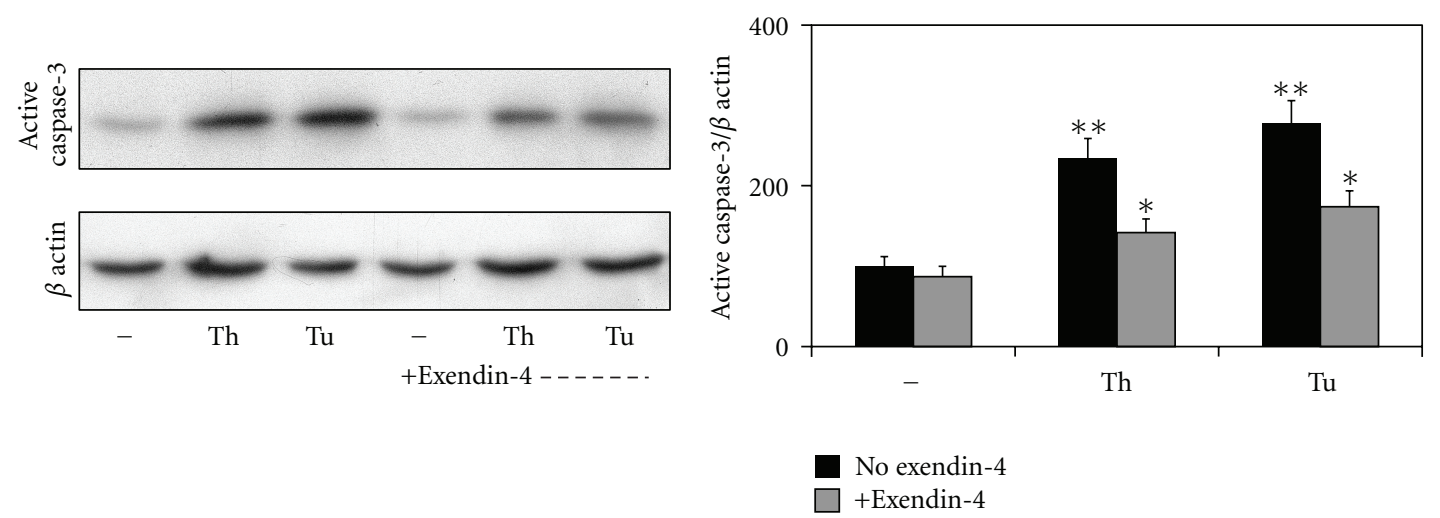

(c)

FIgure 4: Antiapoptotic actions of MnSOD and exendin-4 in MIN6 cells: MIN6 cells cultured on chamber slides were transfected with cDNA encoding MnSOD-GFP chimeric protein. The transfected cells were exposed to a mixture of cytokines ( $2 \mathrm{ng}$ of IL-1 $\beta, 10 \mathrm{ng}$ of TNF$\alpha$ and $10 \mathrm{ng}$ of IFN- $\gamma$ ) for $24 \mathrm{~h}$. The cells were fixed, permeabilized and probed with antibodies specific for the active cleaved fragment of caspase-9 (a) and caspase-3 (b). This was followed by probing with secondary antibodies linked to Cy3. The images were analyzed by digital deconvolution microscopy. The cells expressing MnSOD (green) are protected from cytokine-induced apoptosis. Images from three independent experiments are presented. (c) MIN6 cells were cultured in the absence and presence of exendin-4 (50 nM). ER stress was induced by exposing the cells to thapsigargin (Th; $100 \mathrm{nM}$ ) or tunicamycin (Tu; $1 \mu \mathrm{g} / \mathrm{mL})$ for $24 \mathrm{~h}$. Lysates of the treated cells were analyzed by Western blotting for active caspase- 3 and $\beta$ actin. Band intensities were quantitated by scanning. Results are $\mathrm{M} \pm \mathrm{SE}$ of three independent experiments. ${ }^{* *} P<0.001$ when compared to untreated control. ${ }^{*} P<0.01$ versus respective ER stress control in the absence of exendin- 4 . 

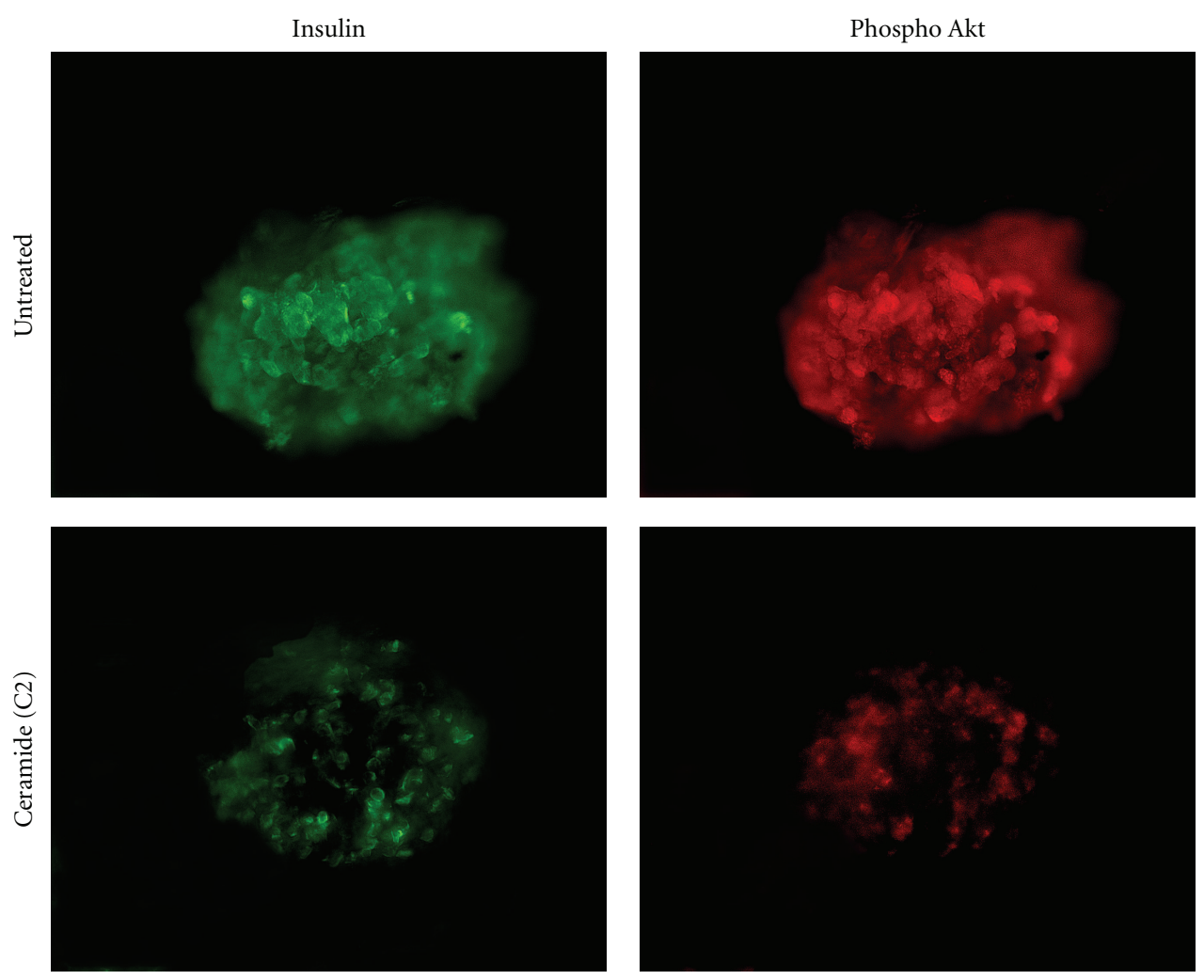

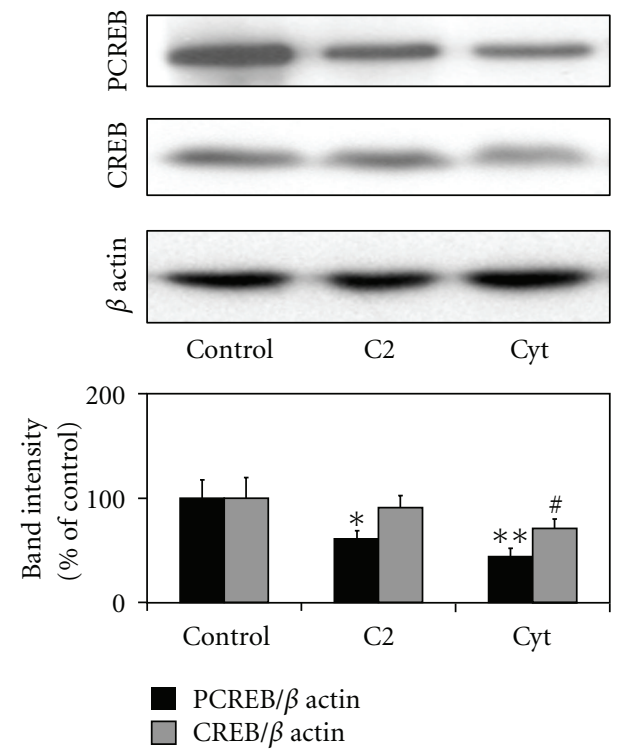

(b)

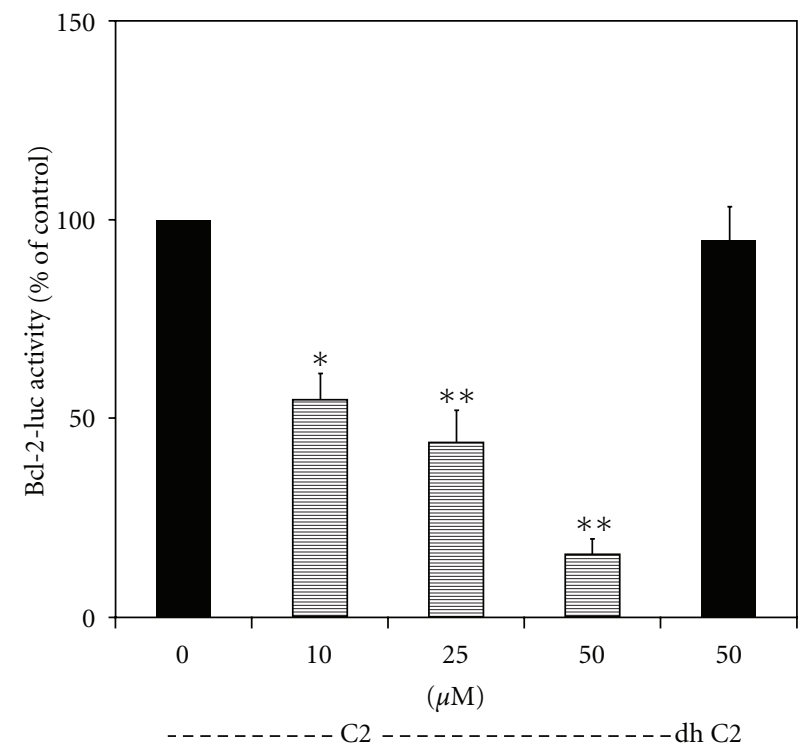

(c)

FIGURE 5: Ceramide is a mediator of cytokine-mediated CREB downregulation. (a) Human islets were exposed to C2 (10 $\mu \mathrm{M}$ ), a synthetic ceramide, for $24 \mathrm{~h}$. The islets were fixed and immunostained for phospho Akt (Thr 308). The images were analyzed by digital deconvolution microscopy. Decrease in the active form of Akt was observed in ceramide-treated islets. (b) Islets were incubated in the absence and presence of $\mathrm{C} 2$ and a combination of cytokines for $24 \mathrm{~h}$ and processed for the Western blot analysis of phosphorylated form of CREB, total CREB and $\beta$ actin. Band intensities were quantitated by scanning. The results are $\mathrm{M} \pm \mathrm{SE}$ of 3 independent experiments. ${ }^{*} P<0.01 ;{ }^{* *} P<0.001$; ${ }^{\#} P<0.05$ compared to untreated control. Active form of CREB was decreased by both C2 and cytokines. (c) MIN6 cells were transfected with a CRE site-containing bcl-2 promoter linked to a firefly luciferase reporter and a constitutively active renilla luciferase (for transfection efficiency). The transfected cells were exposed to increasing concentrations of C2 and $50 \mu \mathrm{M}$ of an inactive analogue (dh) for $24 \mathrm{~h}$. The cells were processed for luciferase activities using a dual luciferase assay kit. The ratio of firefly and renilla luciferase activities was taken as a measure of bcl-2 promoter activity. Bcl-2 promoter activity was inhibited by the ceramide. The results are $\mathrm{M} \pm \mathrm{SE}$ of 4 independent experiments. ${ }^{*} P<0.01 ;{ }^{* *} P<0.001$ compared to untreated control. 

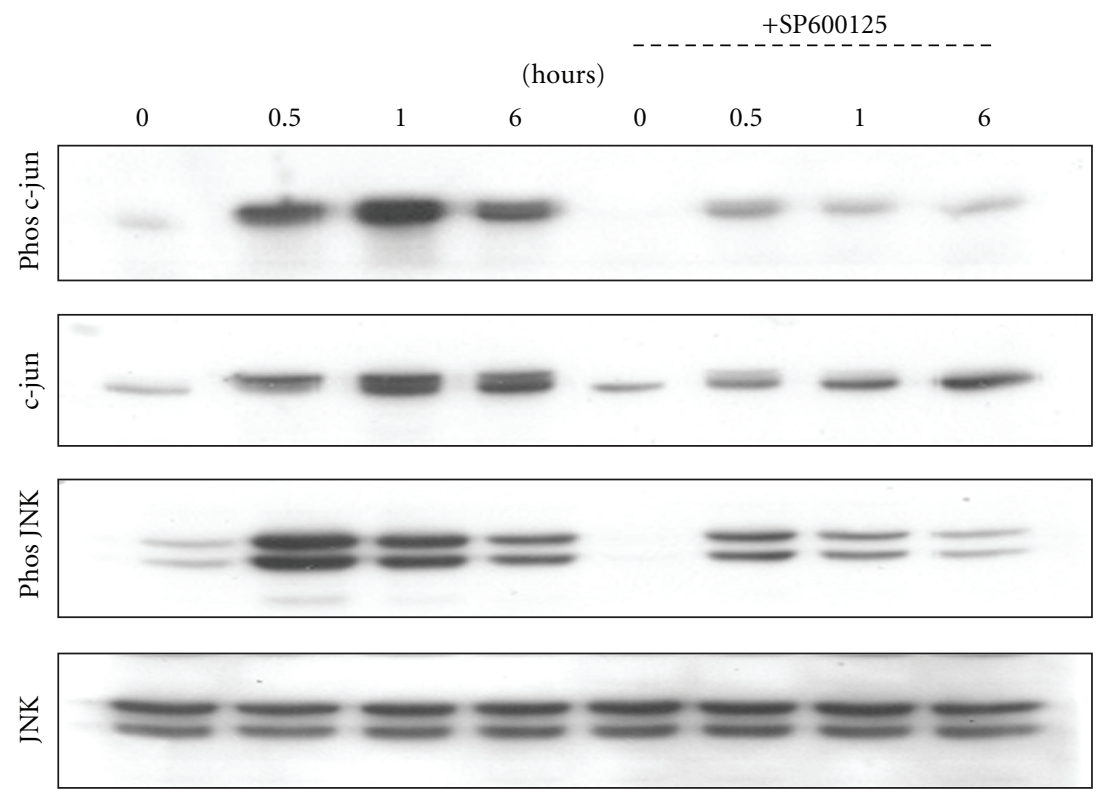

(a)

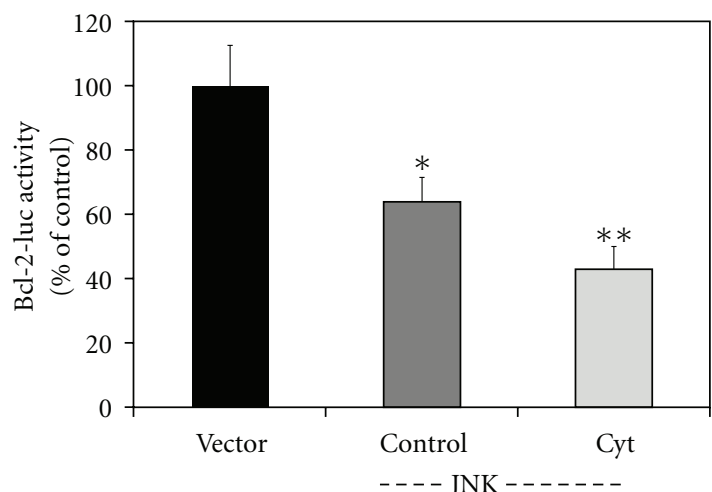

(b)

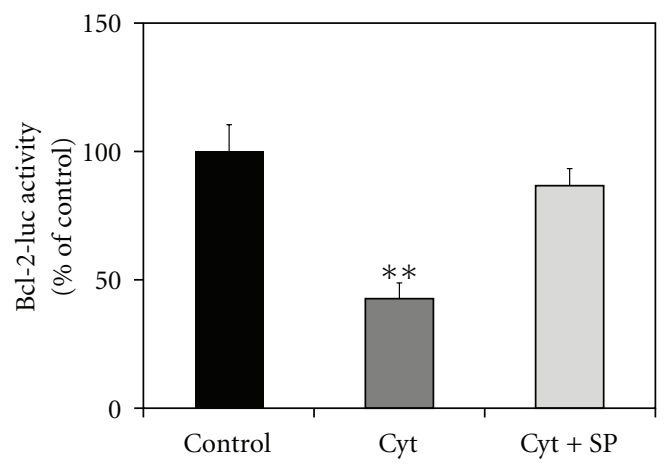

(c)

FIGURE 6: Activation of JNK by cytokines. (a) MIN6 cells were incubated in the absence and presence of $20 \mu \mathrm{M}$ JNK inhibitor, SP600125 and/or a combination of cytokines, IL- $1 \beta(2 \mathrm{ng} / \mathrm{mL})$ TNF- $\alpha(10 \mathrm{ng} / \mathrm{mL})$ and IFN- $\gamma(10 \mathrm{ng} / \mathrm{mL})$ for the indicated time periods. The treated cells were processed for the Western blot analysis of phosphorylated (Phos) c-jun, total c-jun, phosphorylated (Phos) JNK and total JNK. ((b) and (c)) MIN6 cells were transfected with a CRE site-containing bcl-2 promoter linked to a firefly luciferase reporter and a constitutively active renilla luciferase. A combination of plasmid mixture encoding the JNK isozymes or their vector was also included for one experiment (b). Transfected cells were incubated in the absence and presence of a combination of cytokines and JNK inhibitor (SP600125) as indicated for $24 \mathrm{~h}$ followed by the assay for luciferases. Bcl-2 promoter activity was inhibited by cytokines and JNK isozymes. Cytokine action on bcl-2 promoter activity was blocked by the JNK inhibitor. The results are $\mathrm{M} \pm \mathrm{SE}$ of 4 independent experiments. ${ }^{*} P<0.01$; ${ }^{* *} P<0.001$ versus untreated control.

caspase-9 (Figure 4(a)) and caspase-3 (Figure 4(b)) with cy3 (red). MnSOD-expressing cells were identified by the green fluorescence. Staining for active caspase- 9 and -3 did not colocalize with MnSOD-GFP-expressing cells suggesting that these cells are protected from cytokine-induced apoptosis. At least 1000 GFP-expressing cells were examined for each experiment. We also tested the cytoprotective action of exendin-4, a glucagon-like peptide- (GLP-1) analogue, in MIN6 cells following induction of ER stress. Exposure of MIN6 cells to thapsigargin and tunicamycin, inducers of ER stress, caused apoptosis as shown by $135-180 \%(P<0.001)$ increases in the levels of active caspase-3 (Figure 4(c)).
Preincubation of MIN6 cells with exendin- 4 resulted in significant $(P<0.01)$ protection with $40 \%$ decrease in the activation of caspase-3.

3.6. Cytokine-Generated Ceramides Interfere with Activation of $A k t$ and CREB. Ceramides generated by cytokines are known to decrease Akt phosphorylation [23]. Akt plays a significant role in CREB phosphorylation and activation, leading to improved cell survival [24]. Therefore, human islets were exposed to $10 \mu \mathrm{M}$ of synthetic ceramide (C2) and the active phosphorylated form of Akt was immunofluorescently stained with $\mathrm{Cy} 3$ (red) along with staining for 
insulin with FITC (green). Treatment with C2 resulted in decrease in the levels of active form of Akt (Figure 5(a)). Western blot analysis of human islets treated with $\mathrm{C} 2$ or a combination of IL- $1 \beta$, TNF- $\alpha$, and IFN- $\gamma$ showed $40-55 \%$ decrease in PCREB, the active phosphorylated form of CREB (Figure 5(b)). There was also a modest decrease $(P<0.05)$ in CREB levels in cytokine-treated islets. The activity of CRE-site containing bcl-2 promoter was also inhibited in a dose-dependent manner by $\mathrm{C} 2$ whereas the inactive analogue (dh C-2) did not affect the reporter activity (Figure 5(c)). We have previously reported similar downregulation of bcl2 promoter by cytokines [25]. Thus a synthetic ceramide mimics the action of cytokines on $\beta$ cell apoptosis.

\subsection{Activation of JNK Pathway by Cytokines Plays a Role} in Downregulation of Bcl-2 Promoter Activity. Cytokines strongly stimulate the signaling pathways leading to JNK activation. JNK-mediated activation of the transcription factor c-jun plays a critical role in inducing stress-associated genes in $\beta$ cells [26]. A combination of cytokines strongly increased the active phosphorylated forms of JNK isozymes with the peak activation $(P<0.001)$ being observed at 30 min (Figure 6(a)). The levels of total JNK remained the same during the $6 \mathrm{~h}$ incubation period. Activation of JNK led to increases in the active phosphorylated form of c-jun. Maximum activation (370\%) was seen at $1 \mathrm{~h}$. The levels of c-jun also increased (110-235\%) during $6 \mathrm{~h}$ exposure to cytokines as it is an autoregulated gene. Preincubation with the JNK inhibitor resulted in significant $(P<0.01)$ decreases in the phosphorylation of c-jun and in the levels of c-jun. As SP600125 also acts on kinases upstream of JNK, the phosphorylation of JNK itself was reduced. The bcl-2 promoter activity was inhibited when a combination of JNK isozymes was also expressed (Figure 6(b)). Cytokines further enhanced the downregulation of bcl-2 promoter activity by JNK isozymes whereas JNK inhibitor blocked cytokine action on bcl-2 promoter (Figure 6(c)).

\section{Discussion}

Oxidative stress is known to play an important role in $\beta$ cell death in diabetes and in transplanted islets. Autophagy is a physiological mechanism that protects $\beta$ cells under conditions of starvation and hypoxia. However, excessive autophagy resulting from oxidative stress can lead to $\beta$ cell death by crosstalk with apoptosis pathway. In this study, we report the complex modulation of apoptosis pathway genes in human islets exposed to oxidative stress, hypoxia, and cytokines suggesting interactions between pathways involved in cell death as well as cell survival. We demonstrate that autophagic preconditioning of human islets leads to protection against hypoxia-induced apoptosis. Inducers of ER stress were also found to activate autophagy and apoptosis in $\beta$ cells.

Pathway-specific, PCR-based arrays represent a novel technique to determine the expression of a family of genes associated with a specific pathway. We examined the expression of apoptosis pathway genes in human islets exposed to multiple stresses associated with diabetes, islet isolation, and transplantation. We observed significant increases in the expression of genes that are involved in opposing pathways of cell survival and cell death. It is also important to mention four genes, namely BFAR, CARD8, CIDE-A, and BNIP3, as their role in $\beta$ cell apoptosis has not been reported previously. BFAR is a multidomain protein that improves cell survival by interacting with members of extrinsic and intrinsic pathways of apoptosis. Caspase-associated recruitment domain (CARD) family of proteins participates in the activation or inhibition of caspases. CARD8 inhibits the activation of caspase-9. The levels of both BFAR and CARD8 decreased significantly in islets exposed to oxidative stress and hypoxia, suggesting a decrease in antiapoptotic defense in islets. Levels of CIDE-A, a gene that acts downstream of caspases to mediate DNA fragmentation, increased 2- to 3 -folds in islets exposed to stress, suggesting late stages of apoptosis. The expression of BNIP3 which plays an important role in autophagy by disrupting the interaction between Beclin 1 and $\mathrm{Bcl}-2$ was induced by peroxynitrite and hypoxia. BNIP3 promotes mitochondrial autophagy as an adaptive response to hypoxia [27].

Several studies have reported significant interactions between the pathways of apoptosis and autophagy [12, 28, 29]. Apoptosis and autophagy could act as partners to induce cell death. For example, death-associated protein kinase (DAPK) family members, activated by cytokines, are involved in cell death by apoptosis as well as autophagy [12]. Conjugation of ATG5 with ATG12 is an important step in the formation of autophagosomes during basal autophagy. However, when there is excessive autophagy, ATG5 has been reported to interact with components of pathways of apoptosis. Calpain cleaves ATG5 to generate a truncated form of this protein which translocates to mitochondria and induces the release of cytochrome $\mathrm{c}$ from mitochondria to activate the intrinsic pathway. The antiapoptotic proteins $\mathrm{Bcl}-2$ and $\mathrm{Bcl}-\mathrm{xL}$ bind and inhibit Beclin 1-mediated autophagy [30]. This interaction results in the inhibition of autophagy because Beclin 1 will not be able to bind to class III PI 3-kinase (VPS34) and UVRAG, an important step in the initiation of autophagosome formation. Essentially, Bcl-2 keeps autophagy under control (Figure 7). We have demonstrated previously that Bcl-2 levels are regulated by CREB [25]. Therefore, under conditions of CREB downregulation, the pathway of autophagy can be dysregulated. In addition, JNK1-mediated phosphorylation of $\mathrm{Bcl}-2$ also results in the disruption of its interaction with Beclin 1, leading to activation of autophagy [31]. Thus physiological autophagy which improves cell survival can become uncontrolled when $\beta$ cells are exposed to oxidative stress and cytokines.

Autophagy is beneficial to islets in the transplantation setting because it clears organelles damaged by oxidative stress generated during islet isolation and provides energy during starvation (hypoxia). Immediately after transplantation, islets are exposed to hypoxia due to delayed revascularization, leading to a decreased supply of nutrients to $\beta$ cells at the islet core. However, we did not observe protection of islets when autophagy was induced by trehalose, 


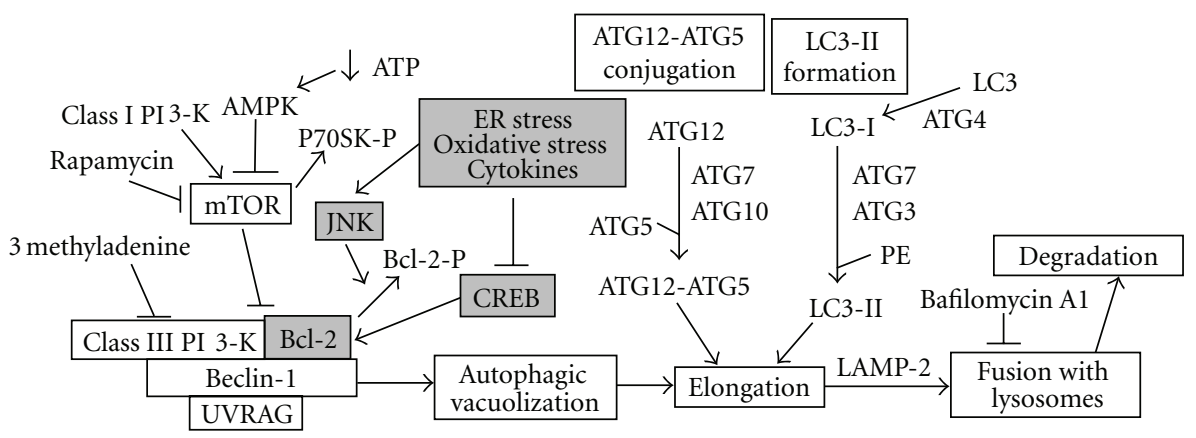

FIGURE 7: Interactions of signaling by ER stress, oxidative stress, and cytokines with the pathways of autophagy: Induction of autophagy requires the assembly of Beclin-1 with class III PI 3 kinase (Vps34) and UVRAG. Rapamycin is an activator of autophagy as it is negatively regulated by class I PI 3 kinase through mammalin target of rapamycin (mTOR). The elongation step involves two ubiquitin-like conjugation system. ATG12 is activated by E1-like ATG7, transferred to E2-like ATG10 and conjugated to ATG5. Similarly, LC3-I is activated by E1-like ATG7, transferred to E2-like ATG3, and conjugated to phosphatidylethanolamine (PE). Inhibitors of autophagy include 3 methyl adenine which inhibits class III PI 3-K and bafilomycin A1 which inhibits the formation of autophagolysosome. Interaction of Bcl-2 with Beclin-1 keeps the autophagic pathway under control. CREB induces the expression of Bcl-2 which is downregulated by ER stress, oxidative stress and cytokines through JNK.

rapamycin and salt solution during hypoxia (Figure 3(b)). Next, we attempted an autophagic preconditioning experiment with the inclusion of other new inducers. There was indeed significant protection in these cells when exposed to hypoxia as shown by decrease in the activation of caspase3 (Figure 3(c)). Especially, FDA-approved drugs including niguldipine and penitrem A showed significant protection. Islets immediately following isolation are likely to display defects in the autophagic machinery and are likely to succumb to hypoxia-induced cell death after transplantation. Thus, there is a need to restore the normal autophagic pathway in cultured islets before transplantation. Current understanding in the islet transplantation field is that it desirable to culture islets for 24-72 h before transplantation since islets can recover from isolation-induced stress and immunogenicity of the islets is reduced. This culture period could also be used to assess and manipulate autophagic pathway to improve transplantation outcome.

The pancreatic $\beta$ cells are particularly vulnerable to oxidative stress-induced injury due to low-level expression of antioxidant enzymes $[32,33]$. Markers of oxidative stress and cellular fragility (RBC) have been shown to be elevated in nondiabetic relatives of type 1 diabetic patients [34]. It has been reported that $\beta$ cell apoptosis could be significantly reduced in NOD mice, an autoimmune diabetic animal model, after administration of an MnSOD mimetic that is known to scavenge free radicals [35]. Proinflammatory cytokines induce the expression of iNOS through NF- $\kappa$ B and GAS sites in iNOS promoter leading to the generation of nitric oxide [36]. When nitric oxide combines with superoxide generated by macrophages or cytokines, highly toxic peroxynitrite is generated. Several studies have demonstrated that peroxynitrite is an important mediator of cytokineinduced $\beta$ cell death in type 1 diabetes [37-39]. In addition, ceramide is known to be one of the mediators of cytokine action. The decrease of active form of Akt by ceramides can interfere with growth factor action on CREB. We observed that peroxynitrite and $\mathrm{C} 2$, a synthetic ceramide, mimic cytokine-induced apoptosis pathway (Table 1 and Figure 5).

Although CREB elicits antiapoptotic pathways in $\beta$ cells, its function can be impaired by other transcription factors in diabetes. For example, JNK and its nuclear target, $c$-jun, have been shown to be mediators of $\beta$ cell-death. JNK-activated c-jun induces the expression of stress-associated genes [40]. Cytokines strongly stimulate the signaling pathways leading to JNK activation [26]. Cell-permeable peptide inhibitors of JNK block cytokine-induced $\beta$ cell death [41]. Inhibition of JNK is being considered as an important strategy to improve $\beta$ cell survival. We have reported that SP600125, a JNK inhibitor, activates CREB [42].

ER stress is known to interact with the pathways of apoptosis and autophagy. For example, Islet amyloid polypeptide (IAPP) which is colocalized and secreted with insulin from $\beta$ cell granules [43] induces $\beta$ cell apoptosis in cultured islets and in type 2 diabetes [44-46]. ER stress is the main mechanism through which IAPP aggregates cause $\beta$ cell apoptosis $[47,48]$. Silencing of IAPP with siRNA improves the survival of cultured human islets [49]. ER stress is also a potent inducer of autophagy $[50,51]$. It has been suggested that autophagy might represent a protective cellular response under conditions of ER stress [52]. We observed formation of LC3-II, a marker for autophagy in MIN6 cells following induction of ER stress with thapsigargin and tunicamycin (Figure 2(c)). ER stress inducers also activated caspase3 which was significantly reduced by exendin-4, a GLP-1 analogue (Figure 4(c)).

It this study, we demonstrate that multiple stresses, generated during islet isolation and transplantation, induce $\beta$ cell death by orchestration of gene expression patterns in 
apoptosis pathway. Although a parallel cell survival pathway is also activated, it is overwhelmed by stress-induced proapoptotic genes. Autophagy, a physiological cytoprotective pathway, interacts with apoptosis when induced in excess in the islet transplantation setting. Therefore, multiple approaches are needed to improve islet transplantation outcome.

\section{Acknowledgments}

This work was carried out with the use of resources and facilities at Denver VA Medical Center. The authors thank Integrated Islet Distribution Program and Islet Cell Resource Centers for providing human islets. This study was supported by a Merit Review grant (NEUD-004-07F) from the Veterans Administration and a Grant from American Diabetes Association (1-06-JF-40) to S. Pugazhenthi.

\section{References}

[1] A. Ashkenazi and V. M. Dixit, "Death receptors: signaling and modulation," Science, vol. 281, no. 5381, pp. 1305-1308, 1998.

[2] D. R. Green and J. C. Reed, "Mitochondria and apoptosis," Science, vol. 281, no. 5381, pp. 1309-1312, 1998.

[3] T. Mandrup-Poulsen, " $\beta$-cell apoptosis: stimuli and signaling," Diabetes, vol. 50, supplement 1, pp. S58-S63, 2001.

[4] S. Nagata, "Fas and Fas ligand: a death factor and its receptor," Advances in Immunology, vol. 57, pp. 129-144, 1994.

[5] M. Moriwaki, N. Itoh, J. Miyagawa et al., "Fas and Fas ligand expression in inflamed islets in pancreas sections of patients with recent-onset type I diabetes mellitus," Diabetologia, vol. 42, no. 11, pp. 1332-1340, 1999.

[6] D. E. Merry and S. J. Korsmeyer, "Bcl-2 gene family in the nervous system," Annual Review of Neuroscience, vol. 20, pp. 245-257, 1997.

[7] S. Ramachandran, N. M. Desai, T. A. Goers et al., "Improved islet yields from pancreas preserved in perflurocarbon is via inhibition of apoptosis mediated by mitochondrial pathway," American Journal of Transplantation, vol. 6, no. 7, pp. 1696$1703,2006$.

[8] D. C. S. Huang and A. Strasser, "BH3-only proteins-essential initiators of apoptotic cell death," Cell, vol. 103, no. 6, pp. 839842,2000

[9] S. N. Willis and J. M. Adams, "Life in the balance: how BH3-only proteins induce apoptosis," Current Opinion in Cell Biology, vol. 17, no. 6, pp. 617-625, 2005.

[10] X. Luo, I. Budihardjo, H. Zou, C. Slaughter, and X. Wang, "Bid, a Bcl2 interacting protein, mediates cytochrome c release from mitochondria in response to activation of cell surface death receptors," Cell, vol. 94, no. 4, pp. 481-490, 1998.

[11] R. Scherz-Shouval and Z. Elazar, "ROS, mitochondria and the regulation of autophagy," Trends in Cell Biology, vol. 17, no. 9, pp. 422-427, 2007.

[12] M. C. Maiuri, E. Zalckvar, A. Kimchi, and G. Kroemer, "Self-eating and self-killing: crosstalk between autophagy and apoptosis," Nature Reviews Molecular Cell Biology, vol. 8, no. 9, pp. 741-752, 2007.

[13] B. J. Marsh, C. Soden, C. Alarcon et al., "Regulated autophagy controls hormone content in secretory-deficient pancreatic endocrine $\beta$-cells," Molecular Endocrinology, vol. 21, no. 9, pp. 2255-2269, 2007.
[14] Y. Uchizono, C. Alarcon, B. L. Wicksteed, B. J. Marsh, and C. J. Rhodes, "The balance between proinsulin biosynthesis and insulin secretion: where can imbalance lead?" Diabetes, Obesity and Metabolism, vol. 9, supplement 2, pp. 56-66, 2007.

[15] N. A. Kaniuk, M. Kiraly, H. Bates, M. Vranic, A. Volchuk, and J. H. Brumell, "Ubiquitinated-protein aggregates form in pancreatic $\beta$-cells during diabetes-induced oxidative stress and are regulated by autophagy," Diabetes, vol. 56, no. 4, pp. 930939, 2007.

[16] A. M. Davalli, L. Scaglia, D. H. Zangen, J. Hollister, S. BonnerWeir, and G. C. Weir, "Vulnerability of islets in the immediate posttransplantation period: dynamic changes in structure and function," Diabetes, vol. 45, no. 9, pp. 1161-1167, 1996.

[17] G. Mattsson, L. Jansson, and P. O. Carlsson, "Decreased vascular density in mouse pancreatic islets after transplantation," Diabetes, vol. 51, no. 5, pp. 1362-1366, 2002.

[18] B. Vasir, P. Reitz, G. Xu, A. Sharma, S. Bonner-Weir, and G. C. Weir, "Effects of diabetes and hypoxia on gene markers of angiogenesis (HGF, cMET, uPA and uPAR, TGF- $\alpha$, TGF- $\beta$, bFGF and Vimentin) in cultured and transplanted rat islets," Diabetologia, vol. 43, no. 6, pp. 763-772, 2000.

[19] J. I. Miyazaki, K. Araki, E. Yamato et al., "Establishment of a pancreatic $\beta$ cell line that retains glucose-inducible insulin secretion: special reference to expression of glucose transporter isoforms," Endocrinology, vol. 127, no. 1, pp. 126132, 1990.

[20] M. M. Bradford, "A rapid and sensitive method for the quantitation of microgram quantities of protein utilizing the principle of protein dye binding," Analytical Biochemistry, vol. 72, no. 1-2, pp. 248-254, 1976.

[21] S. Pugazhenthi, L. Akhov, G. Selvaraj, M. Wang, and J. Alam, "Regulation of heme oxygenase-1 expression by demethoxy curcuminoids through Nrf2 by a PI3-kinase/Akt-mediated pathway in mouse $\beta$-cells," American Journal of Physiology, vol. 293, no. 3, pp. E645-E655, 2007.

[22] L. Zhang, J. Yu, H. Pan et al., "Small molecule regulators of autophagy identified by an image-based high-throughput screen," Proceedings of the National Academy of Sciences of the United States of America, vol. 104, no. 48, pp. 19023-19028, 2007.

[23] H. Zhou, S. A. Summers, M. J. Birnbaum, and R. N. Pittman, "Inhibition of Akt kinase by cell-permeable ceramide and its implications for ceramide-induced apoptosis," Journal of Biological Chemistry, vol. 273, no. 26, pp. 16568-16575, 1998.

[24] S. Pugazhenthit, A. Nesterova, C. Sable et al., "Akt/protein kinase B up-regulates Bcl-2 expression through cAMPresponse element-binding protein," Journal of Biological Chemistry, vol. 275, no. 15, pp. 10761-10766, 2000.

[25] P. Jambal, S. Masterson, A. Nesterova et al., "Cytokinemediated down-regulation of the transcription factor cAMPresponse element-binding protein in pancreatic $\beta$-cells," Journal of Biological Chemistry, vol. 278, no. 25, pp. 23055-23065, 2003.

[26] A. Ammendrup, A. Maillard, K. Nielsen et al., "The c-Jun amino-terminal kinase pathway is preferentially activated by interleukin-1 and controls apoptosis in differentiating pancreatic $\beta$-cells," Diabetes, vol. 49, no. 9, pp. 1468-1476, 2000.

[27] H. Zhang, M. Bosch-Marce, L. A. Shimoda et al., "Mitochondrial autophagy is an HIF-1-dependent adaptive metabolic response to hypoxia," Journal of Biological Chemistry, vol. 283, no. 16, pp. 10892-10903, 2008. 
[28] A. Thorburn, "Apoptosis and autophagy: regulatory connections between two supposedly different processes," Apoptosis, vol. 13, no. 1, pp. 1-9, 2008.

[29] A. L. Edinger and C. B. Thompson, "Death by design: apoptosis, necrosis and autophagy," Current Opinion in Cell Biology, vol. 16, no. 6, pp. 663-669, 2004.

[30] M. C. Maiuri, G. Le Toumelin, A. Criollo et al., "Functional and physical interaction between Bcl-XL and a $\mathrm{BH}$-like domain in Beclin-1," EMBO Journal, vol. 26, no. 10, pp. 25272539, 2007.

[31] Y. Wei, S. Pattingre, S. Sinha, M. Bassik, and B. Levine, "JNK1mediated phosphorylation of Bcl-2 regulates starvationinduced autophagy," Molecular Cell, vol. 30, no. 6, pp. 678688, 2008.

[32] A. P. Robertson, "Chronic oxidative stress as a central mechanism for glucose toxicity in pancreatic islet beta cells in diabetes," Journal of Biological Chemistry, vol. 279, no. 41, pp. 42351-42354, 2004.

[33] M. Tiedge, S. Lortz, J. Drinkgern, and S. Lenzen, "Relation between antioxidant enzyme gene expression and antioxidative defense status of insulin-producing cells," Diabetes, vol. 46, no. 11, pp. 1733-1742, 1997.

[34] E. Matteucci and O. Giampietro, "Oxidative stress in families of type 1 diabetic patients," Diabetes Care, vol. 23, no. 8, pp. 1182-1186, 2000.

[35] K. Haskins, J. Kench, K. Powers et al., "Role for oxidative stress in the regeneration of islet beta cells?" Journal of Investigative Medicine, vol. 52, no. 1, pp. 45-49, 2004.

[36] M. I. Darville and D. L. Eizirik, "Regulation by cytokines of the inducible nitric oxide synthase promoter in insulin-producing cells," Diabetologia, vol. 41, no. 9, pp. 1101-1108, 1998.

[37] J. R. T. Lakey, W. L. Suarez-Pinzon, K. Strynadka et al., "Peroxynitrite is a mediator of cytokine-induced destruction of human pancreatic islet $\beta$ cells," Laboratory Investigation, vol. 81, no. 12, pp. 1683-1692, 2001.

[38] W. L. Suarez-Pinzon, C. Szabó, and A. Rabinovitch, "Development of autoimmune diabetes in NOD mice is associated with the formation of peroxynitrite in pancreatic islet $\beta$-cells," Diabetes, vol. 46, no. 5, pp. 907-911, 1997.

[39] C. A. Delaney, B. Tyrberg, L. Bouwens, H. Vaghef, B. Hellman, and D. L. Eizirik, "Sensitivity of human pancreatic islets to peroxynitrite-induced cell dysfunction and death," FEBS Letters, vol. 394, no. 3, pp. 300-306, 1996.

[40] J. Ham, A. Eilers, J. Whitfield, S. J. Neame, and B. Shah, "cJun and the transcriptional control of neuronal apoptosis," Biochemical Pharmacology, vol. 60, no. 8, pp. 1015-1021, 2000.

[41] C. Bonny, A. Oberson, S. Negri, C. Sauser, and D. F. Schorderet, "Cell-permeable peptide inhibitors of JNK. Novel blockers of $\beta$-cell death," Diabetes, vol. 50, no. 1, pp. 77-82, 2001.

[42] D. Vaishnav, P. Jambal, J. E. B. Reusch, and S. Pugazhenthi, "SP600125, an inhibitor of c-jun N-terminal kinase, activates CREB by a p38 MAPK-mediated pathway," Biochemical and Biophysical Research Communications, vol. 307, no. 4, pp. 855860, 2003.

[43] S. E. Kahn, D. A. D’Alessio, M. W. Schwartz et al., "Evidence of cosecretion of islet amyloid polypeptide and insulin by $\beta$ cells," Diabetes, vol. 39, no. 5, pp. 634-638, 1990.

[44] R. A. Ritzel, J. J. Meier, C. Y. Lin, J. D. Veldhuis, and P. C. Butler, "Human islet amyloid polypeptide oligomers disrupt cell coupling, induce apoptosis, and impair insulin secretion in isolated human islets," Diabetes, vol. 56, no. 1, pp. 65-71, 2007.
[45] A. Lorenzo and B. A. Yankner, "Amyloid fibril toxicity in Alzheimer's disease and diabetes," Annals of the New York Academy of Sciences, vol. 777, pp. 89-95, 1996.

[46] S. Zhang, J. Liu, M. Dragunow, and G. J. S. Cooper, "Fibrillogenic amylin evokes Islet $\beta$-cell apoptosis through linked activation of a caspase cascade and JNK1," Journal of Biological Chemistry, vol. 278, no. 52, pp. 52810-52819, 2003.

[47] C. J. Huang, L. Haataja, T. Gurlo et al., "Induction of en-doplasmic reticulum stress-induced $\beta$-cell apoptosis and accumulation of polyubiquitinated proteins by human islet amyloid polypeptide," American Journal of Physiology, vol. 293, no. 6, pp. E1656-E1662, 2007.

[48] C. J. Huang, C. Y. Lin, L. Haataja et al., "High expression rates of human islet amyloid polypeptide induce endoplasmic reticulum stress-mediated $\beta$-cell apoptosis, a characteristic of humans with type 2 but not type 1 diabetes," Diabetes, vol. 56, no. 8, pp. 2016-2027, 2007.

[49] L. Marzban, A. Tomas, T. C. Becker et al., "Small interfering RNA-mediated suppression of proislet amyloid polypeptide expression inhibits islet amyloid formation and enhances survival of human islets in culture," Diabetes, vol. 57, no. 11, pp. 3045-3055, 2008.

[50] K. Sakaki, J. Wu, and R. J. Kaufman, "Protein kinase C $\theta$ is required for autophagy in response to stress in the endoplasmic reticulum," Journal of Biological Chemistry, vol. 283, no. 22, pp. 15370-15380, 2008.

[51] M. Hoyer-Hansen and M. Jaattela, "Connecting endoplasmic reticulum stress to autophagy by unfolded protein response and calcium," Cell Death and Differentiation, vol. 14, no. 9, pp. 1576-1582, 2007.

[52] M. Ogata, S. I. Hino, A. Saito et al., "Autophagy is activated for cell survival after endoplasmic reticulum stress," Molecular and Cellular Biology, vol. 26, no. 24, pp. 9220-9231, 2006. 


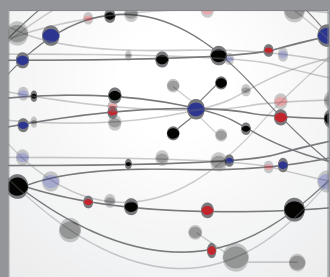

The Scientific World Journal
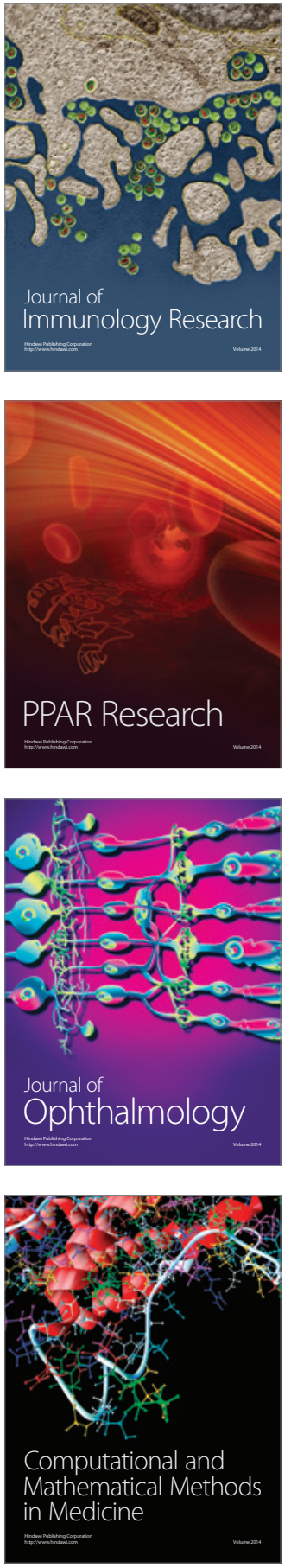

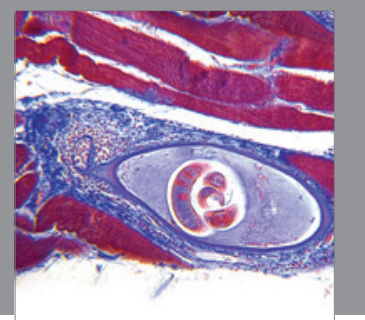

Gastroenterology

Research and Practice
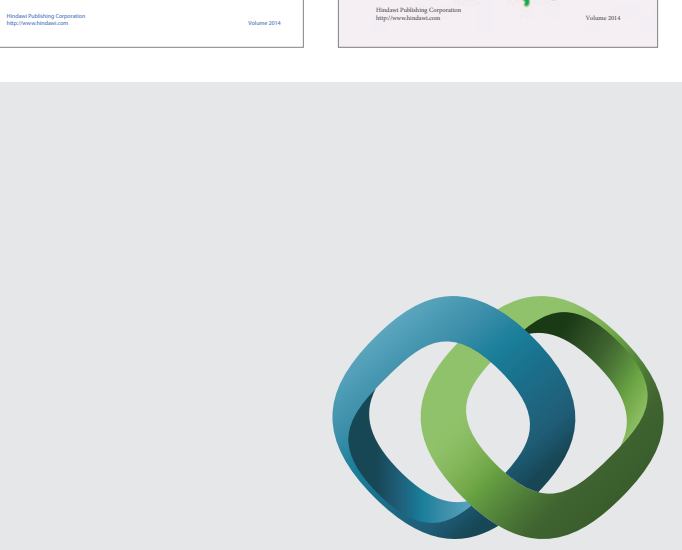

\section{Hindawi}

Submit your manuscripts at

http://www.hindawi.com
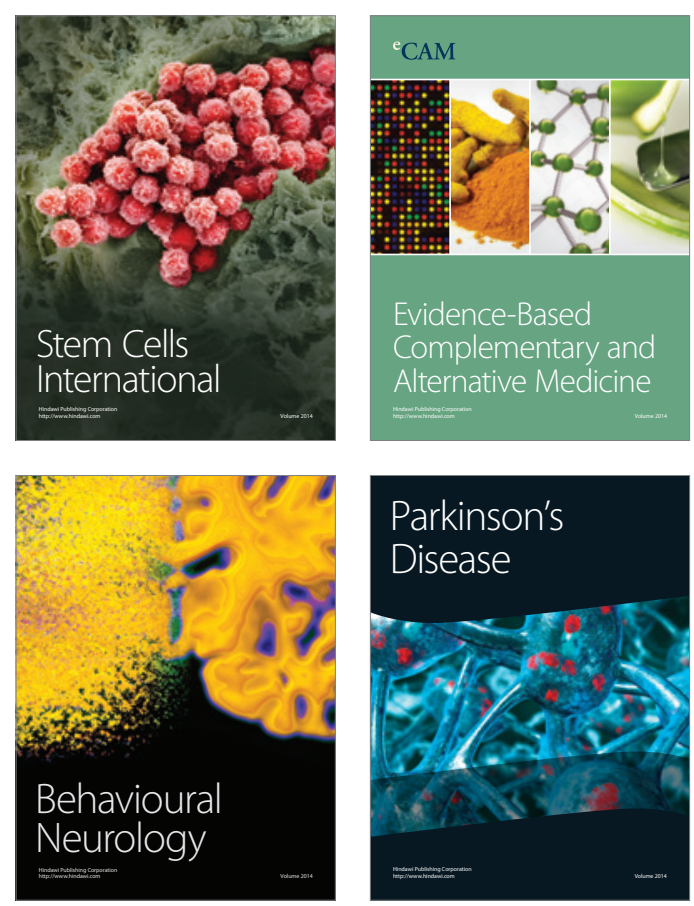

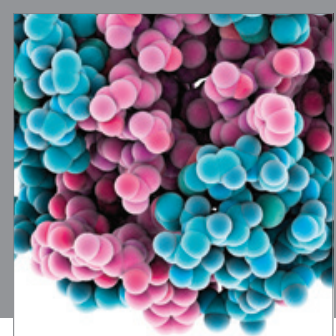

Journal of
Diabetes Research

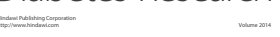

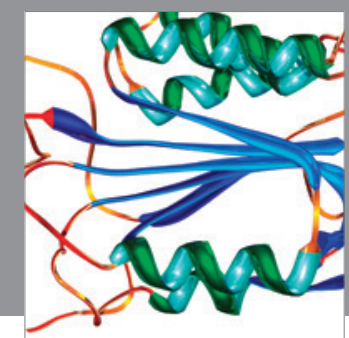

Disease Markers
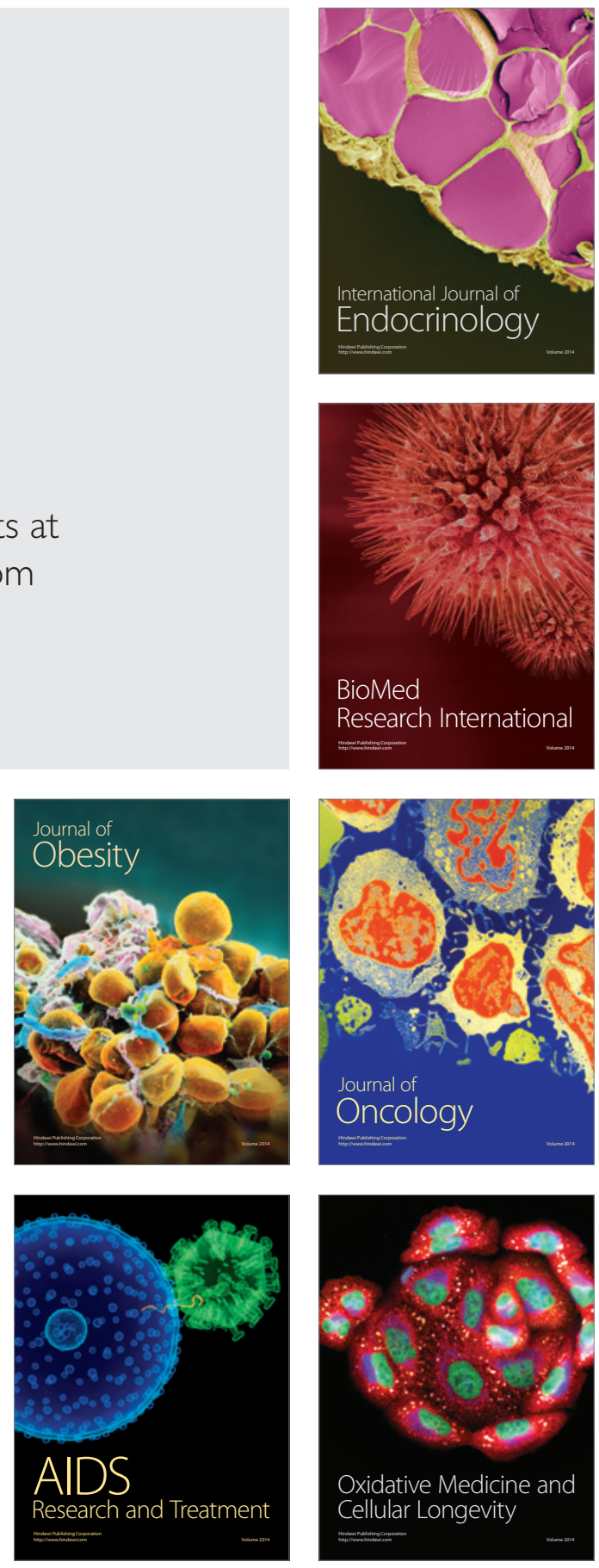